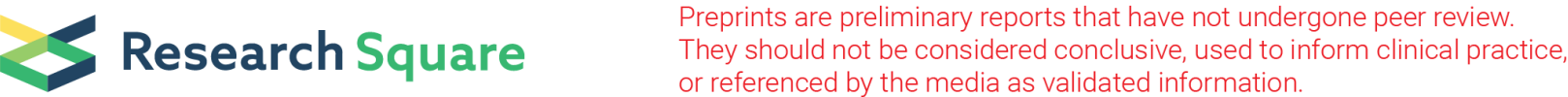

\section{Effect of drought stress during soybean R2-R6 growth stages on sucrose metabolism and its transport from leaf to seed}

\section{Yanli Du}

Shenyang Agricultural University

Qiang Zhao

Shenyang Agricultural University

\section{Liru Chen}

Shenyang Agricultural University

\section{Xingdong Yao}

Shenyang Agricultural University

\section{Huijun Zhang}

Shenyang Agricultural University

\section{Bo Zhang}

Virginia Tech Department of Crop, Soil and Environmental Sciences Blacksburg VA USA

\section{Junjiang Wu}

Soybean Research Institute of Heilongjiang Academy of Agricultural Sciences

Futi Xie ( $\nabla$ snsoybean@sohu.com )

Shenyang Agricultural University

\section{Research article}

Keywords: Glycine max, drought, source-sink relationship, sucrose metabolism, sucrose transporter

Posted Date: November 1st, 2019

DOI: https://doi.org/10.21203/rs.2.16721/v1

License: (c) (1) This work is licensed under a Creative Commons Attribution 4.0 International License. Read Full License 


\section{Abstract}

Background Sucrose is the main photosynthesis product of plants and the fundamental carbon skeleton monomer and energy supply for seed formation and development. Drought stress induces decreased photosynthetic carbon assimilation capacity and seriously affects seed weight in soybean. However, little is known about the relationship between decreases in soybean seed yield and disruption of sucrose metabolism and transport balance in leaves and seeds during the reproductive stages of crop growth.

Results Three soybean cultivars with similar growth periods, 'Shennong17', 'Shennong8', and 'Shennong12' were subjected to drought stress during reproductive growth for 45 days. Drought stress significantly reduced leaf photosynthetic rate, shoot biomass, and seed weight. Drought stress changed the distribution of carbon assimilation products in leaves, thus decreasing starch content and increasing soluble sugar content. Drought stress increased the activities of sucrose phosphate synthase, sucrose synthase, and acid invertase enzymes, and up-regulated the expression levels of GmSPS1, GmSuSy2 , and GmA-INV in leaves. Drought stress decreased the contents of starch, fructose, and glucose in seeds during the late seed filling stages, while it induced sucrose accumulated, which resulted in a decreased hexose-to-sucrose ratio. In developing seeds, the activities of sucrose synthesis and decomposition enzymes and the expression levels of genes related to metabolism were enhanced during early seed development under drought stress; however, under prolonged drought stress, all of them decreased. The expression levels of sucrose transporter genes in seeds were up-regulated under drought stress during early seed development, but down-regulated in leaves and seeds during the middle and late seed filling stages.

Conclusion These results demonstrated that drought stress enhances the capacity for unloading sucrose into seeds and activated sucrose metabolism in seeds during early seed development. At the middle and late seed filling stages, sucrose flow from leaves to seeds was diminished, and the balance of sucrose metabolism was impaired in seeds, resulting in seed mass reduction. The different regulation strategies in sucrose allocation, metabolism, and transport during different seed development stages may be one of the physiological mechanisms for soybean plants to resist drought stress.

\section{Background}

Soybean (Glycine max (L.) Merr.) is the main edible oil, edible protein, and feedstock crop grown globally, with 120 million hectares planted and around 352 million tons of annual production at present [1]. Soybean plant growth and yield are markedly reduced by various abiotic stresses [2]. Drought stress is one of the primary environmental stress conditions that decreases crop productivity and quality, thus posing a serious threat to agriculture [3]. Drought stress during any stages of soybean growth can affect physiological and biochemical metabolisms, ultimately resulting in reduced yield and quality. During the seed filling stage, which is the key stage determining seed size, weight, and composition as well as final soybean yield, soybean plants are more sensitive to water deficits than during vegetative growth. Seed filling involves the processes of carbohydrate mobilization and transport as well as the biochemical 
synthesis of proteins and lipids in developing seeds $[4,5]$. Therefore, understanding the physiological and molecular mechanisms underlying soybean yield under drought stress during the filling stage benefits the improvement of seed yields, thereby increasing food security.

Sucrose, the main photosynthetic product of higher plants, is not only the carbon foundation of physiological metabolism, but also a signaling molecule that coordinates the relationship between plant sources and sinks, playing an important role in plant growth and seed development [6, 7]. In higher plants, the phosphotriose produced by photosynthesis is transported to the cytoplasm and converted to sucrose by enzymes such as sucrose phosphate synthase (SPS) and sucrose phosphate phosphatase. SPS irreversibly catalyzes the formation of sucrose phosphate from uridine diphosphate glucose (UDPG) and fructose 6-phosphate [8]. Activity of SPS, as one of the key rate-limiting enzymes in sucrose synthesis, plays an important role in regulating the sucrose content of plant cells. For example, a decrease in SPS activity in Arabidopsis thaliana inhibited the synthesis of sucrose and resulted in decreased soluble sugar content [9]. Sucrose can be reversibly converted to fructose and UDP-glucose by sucrose synthase (SuSy) or irreversibly hydrolyzed into glucose and fructose by soluble invertases, including cytoplasmic neutral/alkaline invertase $(\mathrm{NI})$ and acid invertase $(\mathrm{Al})[6,10,11]$. Previous studies have shown that the activity of these sucrose metabolic enzymes in plants are directly affected by abiotic stress. For example, drought stress increased SPS activity and decreased SuSy activity in rice plants [12] and decreased the activity of invertase in soybean pods [13]. The genes involved in SPS, SuSy, and invertases (INVs), also played important roles in responding to environmental stresses [14, 15]. RNA sequencing analysis has shown that drought stress before maize tasseling can reduce the expression levels of CWIN, INV, and CIN genes in maize ovaries [16]. The expression levels of SuSy and SPS in cotton leaves were up-regulated as water-logging was prolonged [17]. A more recent study demonstrated that the inhibition of assimilate distribution induced rice grain weights to decrease under heat stress, which was associated with impaired sugar allocation and prominent changes in the expression of sucrose synthasegenes such as OsSuSy2, OsSuSy3, and OsSuSy4 [18].

Seeds are an important sink organ in soybean plants, and their final qualitative and quantitative traits are determined by the seed filling process and nutrient reserve accumulation, which involve biochemical processes related to carbohydrate import and accumulation as well as protein and lipid synthesis [19], which are significantly affected by environmental conditions [20,21]. Seed filling in plants depends upon the directly transported sucrose produced by photosynthesis in leaves, and transport capacity and efficiency are associated with the final seed weight (i.e., seed size). At the same time, sink strength and various physiological metabolic activities in sink cells, especially their metabolic activities, involved in assimilate consumption and accumulation feedback onto and mediate sucrose transport from sources to sinks $[7,22]$. In general, sucrose is transported into sink organs by the phloem via the symplastic or apoplastic pathway [7, 23-25]. For symplastic phloem loading, sucrose transport relies on plasmodesmata, while for apoplastic pathway loading or unloading, sucrose is required by sucrose transporter proteins, such as those in the SWEETs transporter family (SWEETs) and sucrose transporter (SUC), to enable efficient sucrose movement across membranes [26-29]. In Arabidopsis leaves, AtSWEET11 and AtSWEET12 (plasma-membrane Suc effluxers) [30] are responsible for secreting sucrose 
from mesophyll or phloem parenchyma cells into the apoplast. AtSUC2 (the companion cell Suc-specific Suc: $\mathrm{H}^{+}$symporter) is responsible for loading sucrose into the phloem [31, 32]. Previous research has shown that sucrose transporter proteins are affected by abiotic stress. For example, the expression levels of AtSUC2 and AtSUC4 genes in Arabidopsis were induced by various stresses, including salt, low temperatures, osmotic stress, and abscisic acid (ABA) treatment [33]. Durand et al. (2016) [34] reported that the transcript levels of AtSWEET11, AtSWEET12, and AtSUC2 genes in Arabidopsis leaves were upregulated by drought stress, resulting in enhanced sucrose export to roots. Furthermore, heat stress repressed the expression of OSSUT1 in rice leaf, grain, and sheath tissues and limited the assimilate supply for grain development, thereby reducing yield [35]. However, the regulation and management of sucrose transporter proteins in soybean leaves and seeds under drought stress are not fully understood.

Drought stress inhibits the photosynthetic carbon assimilation ability of plants and seriously affects seed weight. Photosynthetic assimilates, such as sucrose, are the carbon backbone of energy metabolism and amino acid biosynthesis for seed growth and development. However, knowledge about the roles of sucrose allocation, metabolism, and transport during soybean development during the seed-filling stages under drought stress is very limited. Therefore, we hypothesized that (1) soybean plants respond to drought stress at the reproductive stage by regulating the balance of sucrose metabolism and transport in leaf and seed tissues and the response mechanisms differ across growth stages and (2) the disruption of metabolism and transport balance results in decreased soybean seed weight. In this study, three soybean cultivars were used to (1) investigate the capacity for assimilation and accumulation of photosynthetic products under drought stress, (2) investigate sucrose metabolism regulation in response to drought stress in soybean leaf tissue and developing seeds by enzyme activity assays and qRT-PCR analyses, and (3) determine the capacity of sucrose transport in soybean leaf tissue and developing seeds under drought stress by qRT-PCR analysis.

\section{Results}

\section{Effect of drought stress on photosynthesis rate, shoot biomass, and seed weight}

Compared to the control, the net photosynthesis rate $\left(P_{\mathrm{N}}\right)$ of the three examined soybean cultivars ['Shennong17' (CV.SN17), 'Shennong8' (CV.SN8), and 'Shennong12' (CV.SN12)] decreased by an average of $63.93 \%$ under drought stress during 15-45 days after flowering (DAF) (Fig. 1A and Table 1). Furthermore, shoot biomass of the three soybean cultivars under drought stress had decreased by $19.77 \%$ at $15 \mathrm{DAF}, 32.44 \%$ at $30 \mathrm{DAF}$, and $48.37 \%$ at $45 \mathrm{DAF}$, respectively, an average decrease of $33.53 \%$ (Fig. 1B and Table 1). There were no significantly differences in seed weight at the early seed development stage (15 DAF) between the control and drought stressed plants. However, seed weight decreased by $41.65 \%$ under drought stress compared to the control during the middle and late seed development stages (30-45 DAF) (Fig. 1C). Genotype (G), plant growth stage (S), treatment (T), and their 
interactions also significantly affected $P_{\mathrm{N}}$, shoot biomass, and seed weight $(P<0.05)$ according to a three-way ANOVA (Tables 1 and 2).

\section{Effect of drought stress on sugar contents in leaves and developing seeds}

In leaves, the starch, fructose, and glucose contents were significantly increased under drought stress compared to the control during 15-45 DAF. However, drought stress significantly increased the sucrose contents of leaves compared with control plants, with an average increase of $33.40 \%$ (Fig. 2A-D). In seeds, the starch, fructose, and glucose contents under drought stress showed different responses during the different seed filling stages (Fig. 2E, G, H). In seeds of the three soybean cultivars, there were no significant differences in starch, fructose, or glucose content during early seed development stages (15 DAF) between the control and drought-stressed plants. However, drought stress significantly decreased the starch, fructose, and glucose contents of the three soybean cultivars during the middle and late seed development stages (30-45 DAF). Compared to the control, the sucrose contents of seeds under drought stress significantly increased by $48.24 \%$ compared to the control during $15-45$ DAF (Fig. 2F). Three-way ANOVA revealed that genotype $(G)$, plant growth stage $(S)$, treatment $(T)$, and their interactions also significantly affected the starch, sucrose, fructose, and glucose contents of leaves and seeds $(P<0.05)$, except the $S \times G$ interaction for starch and the $S \times T, G \times T$ and $S \times G \times T$ interactions for glucose in leaves (Tables 1 and 2).

In leaves, drought stress significantly decreased the hexose-to-sucrose ratio of CV.SN17 and CV.SN8 at 15 DAF and CV.SN12 at 45 DAF by $13.01 \%, 11.75 \%$, and $35.63 \%$, respectively, compared to the control (Fig. $3 \mathrm{~A})$. Meanwhile, compared to the control, the hexose-to-sucrose ratio in seeds of the three soybean cultivars were significantly decreased under drought stress during all reproductive stages (15-45 DAF) (Fig. 3B).

\section{Effect of drought stress on the expression levels of sucrose transporters genes in leaves and developing seeds}

Sucrose is a major photosynthetic product and can be transported from sources to sinks in plants over long distances by sugar transporters (e.g., SWEET and SUC family proteins). To analyze the effect of drought stress on sucrose transport in soybean leaves and seeds, the expression levels of sucrose transporter genes were measured from the same samples used for sugar determination. Five soybean sucrose transporter genes, GmSUC2 (homologous with AtSUC2from Arabidopsis thaliana), GmSWEET6, GmSWEET15, and GmSWEET12 (homologous with AtSWEET11 and AtSWEET12from Arabidopsis thaliana),, and GmSWEET21 (homologous with AtSWEET10from Arabidopsis thaliana) [36] were selected for this study. We first evaluated the expression levels of all selected genes in CV.SN12 at 15 DAF in leaves and seeds under control conditions. Our results showed that GmSWEET6 and GMSWEET15 were 
highly expressed in leaves, while GmSWEET12 and GMSWEET21 were highly expressed in seeds (Fig. S1), which was consistent with previous findings by Patil et al. [36]. Then, we further analyzed the expression levels of GmSUC2, GmSWEET6, and GmSWEET15 in leaves and GmSUC2, GmSWEET12, and GmSWEET21 genes in seeds under control and drought stress treatments.

The qRT-PCR results revealed that drought stress significantly $(P<0.05)$ increased GmSUC2 transcript levels in the leaves at 15 DAF (2.18-fold on average) and up-regulated the transcript levels of GmSUC2, GmSWEET12, and GmSWEET21 in seeds (by 3.76-, 7.04- and 4.61-fold, respectively). However, under prolonged drought stress (i.e., 30-45 DAF), the transcript levels of GmSUC2 in leaves and GmSUC2, GmSWEET12, and GmSWEET21 in seeds were significantly $(P<0.05)$ down-regulated. In addition, drought stress significantly down-regulated the transcript levels of GmSWEET6 and GmSWEET15 in leaves during 15 to 45 DAF (Fig. 4A-F, Tables 1 and 2). Genotype (G), plant growth stage (S), treatment $(T)$, and their interactions also significantly affected expression levels of sucrose transporter genes $(P<$ 0.05 ) in leaves and seeds according to a three-way ANOVA (Tables 1 and 2).

\section{Effect of drought stress on sugar metabolism-related enzyme activities in leaves and developing seeds}

To get a more insight on the effect of drought stress on sucrose utilization and partitioning between leaves and developing seeds, the activities of enzymes related to sucrose metabolism were analyzed. Drought treatment significantly increased SPS, SuSy, and Al enzyme activities in leaves during 15-45 DAF (Fig. 5A-C, Table 1). However, there were no significant differences between the NI activities of control and drought-stressed leaves during 15-45 DAF (Fig. 5D, Table 1). In seeds, the activities of SPS, SuSy, Al, and $\mathrm{NI}$ enzymes were significantly increased at $15 \mathrm{DAF}$ under drought stress compared with the control, while the activities of those four enzymes were all sharply decreased during 30-45 DAF (Fig. 5E$\mathrm{H}$, Table 2). Additionally, the activities of these enzymes related to sucrose metabolism were much higher in seeds than in leaves, even under drought stress (Fig. 5). Three-way ANOVA revealed that genotype (G), plant growth stage $(\mathrm{S})$, treatment $(\mathrm{T})$, and their interactions significantly affected SPS, SuSy, Al, and NI activities $(P<0.05)$ in leaves, except for $S \times G \times T$ interactions for SPS activity, $G \times T$ interactions for SuSy activity, and T for NI activity (Table 1). In seeds, genotype (G), plant growth stage (S), treatment (T), and their interactions significantly affected SPS, SuSy, Al, and Nl activities $(P<0.05)$ except for $\mathrm{G} \times \mathrm{T}$ interactions for SPS activity and $S$ and $S \times G$ interactions for Al activity (Table 2).

\section{Effect of drought stress on the expression levels of key genes involved in sugar metabolism in leaves and developing seeds}

To better understand the mechanisms of sucrose synthesis and degradation metabolism in leaves and seeds under drought stress, a qRT-PCR expression analysis was performed on eight genes belonging to 
the following three groups:

- Four genes encoding putative sucrose phosphate synthases, i.e., GmSPS1, GmSPS2, GmSPS3, and GmSPS4;

- Two genes encoding putative sucrose synthases, i.e., GmSuSy1 and GmSuSy2;

- Two genes encoding putative invertases, i.e., GmA-INV, which encodes acid-invertase, and GmC-INV, which encodes cytosolic neutral/alkaline invertase.

\section{Expression levels of GmSPS1, GmSPS2, GmSPS3, and GmSPS4 in leaves and developing seeds}

The expression levels of four GmSPS genes in leaves showed different responses under drought stress (Fig. 6A-F, Table 1). Drought stress significantly up-regulated the transcript levels of GmSPS1 at 15-45 DAF, with an average 2.27-fold increase compared with the control. However, the expression levels of GmSPS2, GmSPS3, and GmSPS4 were down-regulated during 15 to 45 DAF under drought stress compared to controls. In seeds, the expression levels of GmSPS genes under drought stress responded differently during different seed filling stages (Fig. 6E-H, Table 2). Drought stress significantly promoted the expression levels of GmSPS1, GmSPS2, GmSPS3, and GmSPS4 by averages of 7.97-, 3.99-, 2.60- and 2.03-fold, respectively, at $15 \mathrm{DAF}$ compared with control plants. However, transcripts of the four GmSPS genes were down-regulated during 30 to $45 \mathrm{DAF}$ in drought-stressed plants, except that no significant differences between the control and drought stress treatments in GmSPS4 transcript level were observed in CV.SN17 at 45 DAF and in CV.SN12 at 30 DAF, respectively (Fig. 6E and F and Table 2). Three-way ANOVA revealed that genotype $(G)$, plant growth stage (S), treatment $(T)$, and their interactions also significantly affected the expression levels of GmSPS1, GmSPS2, GmSPS3, and GmSPS4 $(P<0.05)$ in leaves and seeds, except T for GmSPS4 in seedsTables 1 and 2).

\section{Expression levels of GmSusy1 and GmSusy2 in leaves and developing seeds}

In leaves, drought stress significantly up-regulated the transcript levels of GmSusy 1 during 15-45 DAF by an average of 2.11-fold in CV.SN8 and 1.57-fold in CV.SN12, respectively, relative to control plants. However, there were no significant differences in GmSusy 1 transcript levels between the control and drought stress treatments in CV.SN17 during 15-45 DAF (Fig. 7A and Table 1). The transcript levels of GmSusy2 were up-regulated under drought stress in leaves during 15-45 DAF compared to the control (Fig. 7B and Table 1). In seeds, the expression levels of GmSusy1 and GmSusy2 under drought stress responded differently across seed filling stages (Fig. 7E and F, Table 2). Drought stress significantly upregulated the expression levels of GmSusy1 and GmSusy2 at 15 DAF compared to control plants. However, GmSuSy 1 and GmSuSy2 transcripts were sharply down-regulated in drought-stressed plants during 30 to 45 DAF (Fig. 7E and F, Table 2). According to a three-way ANOVA, genotype (G), plant growth 
stage (S), treatment $(\mathrm{T})$, and their interactions significantly affected the expression levels of GmSusy1 and GmSusy $2(P<0.05)$ in leaves and seeds, except $\mathrm{G} \times$ T for GmSusy 1 in seeds (Tables 1 and 2).

\section{Expression levels of GmA-INV and $G m C$-INV in leaves and developing seeds}

In leaves, drought stress significantly up-regulated the expression levels GmA-INV and GmC-INV during 15 to $45 \mathrm{DAF}$ (Fig. 7C and Table 1), except that there were no significant differences between the control and drought stress treatments in $\mathrm{GmC}$-INV transcript level in CV.SN17 at 45 DAF and in CV.SN12 at 15 DAF, respectively. In seeds, the expression levels of $G m A-I N V$ and $G m C$-INV under drought stress responded differently across seed filling stages (Fig. $7 \mathrm{G}$ and $\mathrm{H}$, Table 2). Drought stress significantly up-regulated the expression levels of GmA-INV and GmC-INV at 15 DAF compared with control plants. However, GmA$I N V$ and $G m C-I N V$ transcripts were all sharply down-regulated in drought-stressed seeds during 30 to 45 DAF (Fig. $7 \mathrm{G}$ and $\mathrm{H}$ and Table 2). A three-way ANOVA revealed that genotype (G), plant growth stage (S), treatment $(\mathrm{T})$, and their interactions also significantly affected the expression levels of GmA-INV and GmC-INV $(P<0.05)$ in leaves and seeds (Tables 1 and 2$)$.

\section{Discussion}

Many studies have shown that soybean growth, development, and yield are negatively affected by drought stress $[13,37,41,42]$. Drought stress inhibits the production of photosynthetic products owing to decreases in leaf photosynthetic capacity $[38,39]$ and the acceleration of leaf wilting and senescence $[5$, 40]. Drought stress during the reproductive phase, especially the seed filling stage,decreases the production and mobilization of assimilates to developing seeds, which can result in considerable yield losses $[13,37,41,42]$. In this study, drought stress during soybean seed filling stages significantly decreased $P_{N}$, inhibited shoot growth, and decreased seed weight (Fig. 1). Three soybean cultivars were used to study carbon assimilation, sucrose metabolism, and transport regulation mechanisms in response to drought stress during seed filling.

\section{The balance of carbon assimilation and carbon metabolism in soybean leaves was disturbed by drought stress}

Drought stress significantly affected the distribution of carbohydrates in leaves, thus decreasing starch content, while increasing the content of soluble sugars (i.e., sucrose, fructose, and glucose), especially during the middle and late seed-filling stages (Fig. 2). This was consistent with previous research showing that drought stress decreased carbon assimilation while increasing accumulation of soluble carbohydrate content $[34,43,44]$. This regulation mechanism seemed to benefit plant growth and seed development, as higher sugar content of leaf tissue is responsible for sucrose phloem loading and flowing into sink organs, such as roots and seeds [45]. On the other hand, soluble sugars are important 
osmoprotectants and energy sources for plant cells under drought stress [46]. A previous study showed that the increased soluble sugars, mainly sucrose, improved plant tolerance to abiotic stress [47].

The accumulated soluble sugars might be related to drought stress-induced sugar metabolism regulation in soybean leaves. It was well known that SPS plays a vital role in recycling free UDPG and fructose to increase the sucrose content of leaves [8], while SuSy, Al, and NI are three important enzymes involved in sucrose decomposition [48-50]. The activities of SPS, SuSy, and Al enzymes in the three soybean cultivars leaves were significantly increased by drought stress during the soybean seed filling stage (Fig. 5A-D). Accordingly, the expression levels of GmSPS1, GmSuSy genes (i.e., GmSuSy 1 and GmSuSy2), and GmA-INV genes were all up-regulated by drought stress, with the exception that drought stress had no significant effect on the transcription of GmSuSy 1 in CV.SN17 leaves (Figs. 6 and 7). The increased sucrose metabolic enzyme activities in soybean leaves under drought stress improved sucrose utilization efficiency and promoted soluble sugar accumulation. Notably, GmSPS1 appeared to have a predominant role in sucrose synthesis in leaves compared to GmSPS2, GmSPS3, and GmSPS4 under drought stress. This complex transcriptional regulatory mechanism of GmSPS genes in soybean leaves under drought stress requires further investigated.

Starch can be converted by triose phosphates in chloroplasts and stored as an energy source in leaves [51]. Thus, starch content is an important indicator of leaf source capacity. Drought stress induced a significant decrease in the starch content of soybean leaves (Fig. 2A), which might be related to increased starch decomposition. Previous studies have shown that osmotic stress triggers starch degradation into glucose and maltose in leaves, leading to sugar accumulation $[52,53]$. It was apparent that the modification in partitioning between sucrose and starch in leaves occurred in response to drought stress.

\section{Drought stress affects sucrose transport from leaves to seeds}

Carbohydrates, mainly sucrose, are synthesized in mature source leaves and translocated to sink tissues (such as developing seeds) in higher plants to sustain heterotrophic metabolism and growth or for storage as sucrose or starch $[10,54]$. Previous studies have shown that the capacity of sucrose transport in higher plants is closely related to the expression of SWEET and SUC proteins in source and sink organs [25, 36, 55]. For example, Chen et al. (2012) [30] reported that a sweet11/12 mutation in Arabidopsis thaliana resulted in a reduction of sucrose excretion by leaves, and Dasgupta et al. (2014) [56] reported that up-regulation of SUC2 increased $\left[{ }^{14} \mathrm{C}\right]$ sucrose uptake into the veins of leaf discs and higher phloem loading of sucrose. In the current study, drought stress regulated the expression of sucrose transport genes in soybean leaves and seeds at different seed development stages, causing (1) the inhibition of sucrose export in mesophyll cells, but the promotion of sucrose uptake by soybean seeds in early seed development, and (2) the inhibition of sucrose transport from leaves into seeds during later seed development (Fig. 4A-F, Fig. 8). 
During early seed development, drought stress up-regulated the expression of GmSUC2 in leaves and GmSUC2, GmSWEET12, and GmSWEET21 in seeds (Fig. 4A, D-F, Fig. 8), which may promote more sucrose flowing into seeds to meet the energy demand for seed development $[55,57,58]$, with minimum seed weight reduction occurring (Fig. 1C). However, the down-regulated expression of GmSWEET6 and GmSWEET15 genes in soybean leaves during early seed development (Fig. 4E and F) can induce sucrose accumulation in soybean mesophyll cells $[30,36]$. One reasonable explanation for the results is that the functions of GmSWEET6/15and GmSUC2proteins in leaves differ in response to early drought stress, as SWEET proteins are responsible for taking up sucrose from mesophyll cells or phloem parenchyma cells into the apoplast, and SUC proteins are responsible for loading sucrose into the phloem (Fig. 8, [30-32]). The up-regulation of GmSUC2 by drought stress might also mediate the ABA signaling pathway, as reported for AtSUC2 in Arabidopsis [33]. The higher sugar content of leaves helped maintain mesophyll cell activity and the photosynthetic ability to respond to drought stress.

Drought stress significantly reduced the expression levels of sucrose transport genes in leaves and seeds during 30-45 DAF (Fig. 4A-F, Fig. 8). Two possible drought response mechanisms were proposed to explain this phenomenon: (1) drought stress created a signal that directly resulted in down-regulation of sucrose transport genes and the reduction of seed growth or (2) drought stress inhibited seed growth, thereby decreasing demand for sucrose in seeds, which exceeded the sucrose utilization capacity of seeds and, in turn, inhibited the expression of sucrose transport genes, thus ultimately reducing sucrose flow to seeds. Previous studies have shown that drought stress directly regulated expression levels of sucrose transport genes, such as AtSWEET11, AtSWEET12, and AtSUC2, thus mediating sucrose export from sources to sinks [34]. Water deficiency caused by drought stress in developing seeds can inhibit the synthesis and accumulation of seed reserves and block cell division $[4,59,60]$, which might reduce energy demand and promote the early termination of the seed filling process. Thus, further experiments are needed to determine the mechanisms by which soybean sucrose transporter gene expression was affected by drought stress.

\section{Drought stress affects carbohydrate enrichment and metabolism in developing seeds}

The seed filling period is the terminal stage for forming propagules in spermatophytes, and it involves several physiological and biochemical processes, such as the import of constituent molecules as well as carbohydrate, protein, and lipids synthesis in seeds [19]. These processes were significantly affected by various abiotic stresses and affected the final seed quality and weight $[20,21,60]$. When soybean plants were subjected to drought stress, seed starch content and seed weight were markedly decreased during the late seed filling stages (Fig. 1C and 2E) compared to the control, while sucrose concentration was significantly increased (Fig. 2F). These results were similar to previous findings in lupin seeds when a short-term water deficit was imposed during seed development [40]. Previous studies have shown that the activities of sucrose synthase and soluble invertase decrease in drought-stressed seeds $[13,40]$. Interestingly, inconsistent with this previous conclusion, the activity levels of SPS, SuSy, NI, and Al also 
decreased in drought-stressed soybean seeds during the late drought-stress period (30-45 DAF) in our study; however, the activity levels of these four sucrose metabolism enzymes all also increased during the early drought-stress period (15 DAF) (Fig. 5E-H, Fig. 8). Improved SPS activity can accelerate sucrose recycling and utilization [61]. SuSy, $\mathrm{NI}$, and $\mathrm{Al}$, which were also affected by drought stress, are three key enzymes involved in seed storage through their influence on sink activity $[40,62]$. Soybean plants were undergoing the beginning of seed formation during the early drought stress period (at $15 \mathrm{DAF}$ ), that is, sink growth needed more nutrition and starch accumulation during this period. Thus, increasing the activity levels of SPS, SuSy, $\mathrm{NI}$, and $\mathrm{Al}$ enzymes was important for the improvement of drought resistance at the beginning of seed formation. This can be well verified by the constant contents of starch, fructose, and glucose in early drought-stressed developing seeds (Fig. 2E-G), which contributed to maintaining seed weight (Fig. 1C). However, during seed development and prolonged drought stress at 30-45 DAF, the activity levels of SPS enzymes decreased (Fig. 5E, Fig. 8) and sucrose re-synthesis was reduced, which suggests that sucrose recycling was limited. Meanwhile, the activity levels of SuSy, $\mathrm{NI}$, and Al were decreased during 30-45 DAF (Fig. 5F-H, Fig. 8), suggesting that decomposition of sucrose was inhibited $[48,63]$. This was confirmed by the reduction of fructose and glucose content in drought-stressed seeds (Fig. $2 \mathrm{G}$ and 2F). Previous studies have indicated that high hexose-to-sucrose ratios are favorable to cell division during reproductive development $[13,62,64]$. However, a decreased hexose-to-sucrose ratio was observed in drought-stressed seeds (Fig. 3B), which suggests that seed cell division was inhibited by drought stress. Thus, the decline in sucrose decomposition and recycling ability altered carbohydrate composition and allocation in seeds, which resulted in sucrose accumulation in seeds despite seed weight reduction (Fig. 1C and 2F). The change in expression of GmSPSgenes in seeds of the three cultivars (Fig. 6E-H) reflected the change in SPS activity (Fig. 5E), which suggests that the four GmSPS homologues acted together to control sucrose synthesis in drought-stressed seeds. Previous studies have reported that loss-of-function invertase mutants had lower invertase activity and thus lower seed weights [65-68], which indicated that invertase activity had a critical role in the regulation of seed development. The role of SuSy gene was also important for carbon allocation during seed filling, especially when subjected to drought, cold, and heat stress $[18,69]$. In our study, a similar trend in expression levels among GmSuSy genes, GmA-INV, and GmC-INV (Fig. 7E-H) reflected trends in SuSy, Al, and NI activity levels (Fig. $5 \mathrm{~F}-\mathrm{H}$ ) under drought stress. These results strongly suggest that GmSuSy, GmA-INV, andGmC-INV proteins acted together to modulate sucrose decomposition in developing seeds under drought stress.

\section{Conclusion}

Drought stress during reproductive growth stages induced soybean seed weight to decrease through mechanisms that included drought stress regulating photosynthetic assimilate production, sugar metabolism, and transport in leaves and seeds. Drought stress inhibited the production of photosynthetic products, changed the distribution of photosynthetic products, and ultimately decreased the starch content of leaves. Drought stress enhanced the utilization efficiency of sucrose by increasing the activity levels of sucrose synthesis and decomposition enzymes and reduced the secretion of sucrose from mesophyll cells by inhibiting SWEET transport capacity in leaves. Together, these mechanisms increased 
the content of sucrose in leaves in response to drought stress. At the beginning of seed formation, drought stress upregulated the expression levels of GmSUC2, GmSWEET12, and GmSWEET21 in seeds to promote more sucrose in seeds and increase the activities of sucrose synthesis and decomposition enzymes to enhance utilization efficiency of sucrose in seeds. This enabled soybean plants to reserve energy and better tolerate drought stress. However, during the late seed filling stages, drought stress seriously weakened the capacity of sucrose transport from leaves to seeds and inhibited the decomposition and circulation of sucrose, which was accompanied by a decreased hexose-to-sucrose ratio in seeds, together resulting in seed weight loss. In short, drought stress disrupted the balance of sucrose metabolism and transport in leaves and seeds at reproductive stages, which seemed to be the main mechanism through which drought caused soybean seed weight to decrease.

\section{Methods}

\section{Experimental design and treatment}

Three soybean cultivars, 'Shennong17' (CV.SN17, 44.26\% protein (dry base) and $20.77 \%$ oil), 'Shennong8' (CV.SN8, $42.89 \%$ protein and $20.40 \%$ oil), and 'Shennong12' (CV.SN12, 38.89\% protein and $22.09 \%$ oil), used in this research were obtained from the Soybean Institute, College of Agriculture, Shenyang Agricultural University, Liaoning, PR China. These soybean cultivars are currently used in local production and no permission was needed for the collection of these materials. The three soybean cultivars have similar growth periods and were used as independent biological replicates in this study. This pot cultivation experiment was conducted at the experimental station of Shenyang Agricultural University $\left(41^{\circ} 82^{\prime} \mathrm{N}, 123^{\circ} 57^{\prime} \mathrm{E}\right)$ from May to September 2018 . Average-sized soybean seeds were selected and planted directly into pots $(25 \times 30 \times 25 \mathrm{~cm})$ with $12.5 \mathrm{~kg}$ of soil per pot, and plants were then grown in a greenhouse. The soil ( $\mathrm{pH} 7.33$ ) contained $16.77 \mathrm{~g} / \mathrm{kg}$ soil organic matter, $0.77 \mathrm{~g} / \mathrm{kg}$ total nitrogen, 0.07 $\mathrm{g} / \mathrm{kg}$ available nitrogen, $0.02 \mathrm{~g} / \mathrm{kg}$ available phosphorus, and $0.14 \mathrm{~g} / \mathrm{kg}$ available potassium. Experiments were conducted according to a randomized complete block design with three replicates. Each pot contained two plants undergoing the same treatment, which were together considered as a single experimental unit. Drip irrigation was used to keep the soil moist at $70-80 \%$ of the field water-holding capacity until soybeans flowered. When about $50 \%$ of the flowers on the main stems of soybean were open (R2 growth stage, according to Fehr et al. (1971) [70]), different water treatments were applied to the soybean plants. Under treatment 1, normal watering (control) was conducted so as to maintain the relative soil water content at a field water holding capacity of $70-80 \%$. Under treatment 2 , a drought stress treatment was employed, that is, the relative water content was maintained at a field water holding capacity of $35-40 \%$. Soil water levels were monitored using a soil moisture probe (Field Scout TDR 300 Probe, Spectrum Technologies, Inc., Aurora, IL, United States) every day. The first day after the drought stress treatment, i.e., the day after flowering (DAF), was recorded as $1 \mathrm{DAF}$, and the drought stress treatment lasted for 45 days. Tissue samples were taken at 15, 30, and $45 \mathrm{DAF}$, which represented the beginning of the seed formation phase (15DAF, R4 growth stage), the start of the seed filling phase (30 DAF, R5 growth stage), and the rapid seed filling phase (45 DAF, R6 growth stage). 


\section{Sampling}

To measure the shoot biomass and seed weight per plant, the aboveground parts of soybean plants were cut at the node of each plant's cotyledon, oven-dried at $105^{\circ} \mathrm{C}$ for $30 \mathrm{~min}$, and maintained at $85^{\circ} \mathrm{C}$ until the weight was constant. To measure leaf physiological and biochemical parameters, the third fully expanded leaf on each plant (from the top of the main stem) was selected at 9:30-11:00 and divided into two parts along its main veins; one half was immediately frozen in liquid $\mathrm{N}_{2}$ and stored at $-80^{\circ} \mathrm{C}$ for subsequent enzyme activity assays and gene expression analysis. The other half was oven-dried for the determinations of starch, sucrose, glucose, and fructose contents.

To measure the seed physiological and biochemical parameters, the seeds were also collected at 9:3011:00 and similarly divided into two parts; one half was immediately frozen in liquid $\mathrm{N}_{2}$ and stored at $80^{\circ} \mathrm{C}$ for subsequent enzyme activity assays and gene expression analysis. The other half was oven-dried for the determinations of starch, sucrose, glucose, and fructose contents.

\section{Measurement of net photosynthetic rate}

To measure photosynthetic parameters, the third fully expanded leaf on each plant (from the top of the main stem) was selected at 9:30-11:00 and measured using a LI-6800 portable photosynthesis system (LI-COR Inc., Lincoln NE, USA). According to the method described by Li et al. 2017 [71], the lightsaturation point was set to $1,200 \mu \mathrm{mol}$ (photon) $\mathrm{m}^{-2} \mathrm{~s}^{-1}$ to measure the net photosynthetic rate (Fig. S2). The ambient temperature of each measured soybean leaf was kept at $30^{\circ} \mathrm{C}$. The $\mathrm{CO}_{2}$ concentration was $400 \mu \mathrm{mol}\left(\mathrm{CO}_{2}\right) \mathrm{mol}^{-1}$, relative humidity was $60-65 \%$, and air flow was $500 \mu \mathrm{mol} \mathrm{s}{ }^{-1}$.

\section{Carbohydrate measurement}

Carbohydrates were extracted from leaves and seeds and then quantified using a modified version of the method described by Hu et al. 2018 [72]. About $0.1 \mathrm{~g}$ of ground sample was extracted with $80 \%(\mathrm{~V} / \mathrm{V})$ ethanol at $80^{\circ} \mathrm{C}$ for $30 \mathrm{~min}$, and then centrifuged at $10,000 \times \mathrm{g}$ for $10 \mathrm{~min}$. The residue was extracted two more times using $80 \%$ ethanol. The three supernatants were combined, and $80 \%$ ethanol was added to reach a total volume of $5 \mathrm{~mL}$. Then, $20 \mu \mathrm{L}$ extract samples were continuously incubated three times with glucose assay reagent (Glucose Assay kit; Sigma-Aldrich, St. Louis, MO, USA) at $30^{\circ} \mathrm{C}$ for $15 \mathrm{~min}$, with 10 $\mu \mathrm{L}$ of phosphoglucose isomerase $\left(0.25\right.$ units, Sigma-Aldrich) at $30^{\circ} \mathrm{C}$ for $15 \mathrm{~min}$, and then with $10 \mu \mathrm{L}$ of invertase (83 units, Sigma-Aldrich) at $30^{\circ} \mathrm{C}$ for $60 \mathrm{~min}$, respectively. The absorbance was recorded at $\mathrm{A}_{340}$ $\mathrm{nm}$ after each incubation step to determine glucose, fructose, and sucrose contents, respectively.

The ethanol-insoluble residue was used for starch extraction. After removing ethanol by evaporation, 2 $\mathrm{mL}$ of distilled water was added, and samples were incubated at $100{ }^{\circ} \mathrm{C}$ for $15 \mathrm{~min}$. Then $2 \mathrm{~mL}$ of 9.2 mol L-1 $\mathrm{HClO}_{4}$ was added into samples for $15 \mathrm{~min}$ to hydrolyze starch. Thereafter, $4 \mathrm{~mL}$ of distilled water 
was added to samples, which were then centrifuged at $4000 \times \mathrm{g}$ for $10 \mathrm{~min}$. The residue was extracted one more time using $2 \mathrm{~mL}$ of $4.6 \mathrm{~mol} \mathrm{~L}^{-1} \mathrm{HClO}_{4}$. Then, the two supernatants were combined and distilled water was added to reach a total volume of $20 \mathrm{~mL}$. According to the method by Kuai et al. 2014 [17], the starch content was determined by spectrophotometry using anthrone reagent at a $A_{620} \mathrm{~nm}$ wavelength.

Hexose concentration was calculated as the summation of fructose and glucose concentrations, from which hexose-to-sucrose ratios were calculated.

\section{Enzyme extraction and analysis}

According to Liu et al. 2013 [73], the frozen fresh samples were ground in liquid nitrogen and then homogenized with cooled extraction buffer containing $100 \mathrm{mM}$ Tris- $\mathrm{HCl}(\mathrm{pH}$ 7.2), 1 mM EDTA, $10 \mathrm{mM}$ $\mathrm{MgCl}_{2}, 10 \mathrm{mM} \beta$-mercaptoethanol, 10\% polyvinylpyrrolidone (PVP), and 12.5\% $(\mathrm{v} / \mathrm{V})$ glycerin. The homogenate was centrifuged at $15,000 \times \mathrm{g}$ for $15 \mathrm{~min}$ at $4^{\circ} \mathrm{C}$. All extraction procedures were conducted at $0-4^{\circ} \mathrm{C}$.

The reaction buffer for the SPS activity assay contained $12 \mathrm{mM}$ UDP-glucose, $40 \mathrm{mM}$ fructose-6-P, 200 $\mathrm{mM}$ Tris- $\mathrm{HCl}(\mathrm{pH} 7.0), 40 \mathrm{mM} \mathrm{MgCl}_{2}$, and $200 \mu \mathrm{L}$ of extract. For the SuSy activity assay, the reaction buffer contained $12 \mathrm{mM}$ UDP, $40 \mathrm{mM}$ sucrose, $200 \mathrm{mM}$ Tris-HCl (pH 7.0), $40 \mathrm{mM} \mathrm{MgCl}$, and $200 \mu \mathrm{L}$ of extract. The reaction was initiated by incubating the enzyme at $30^{\circ} \mathrm{C}$ for $30 \mathrm{~min}$ and stopped using 100 $\mu \mathrm{L}$ of $2 \mathrm{~mol} \mathrm{~L}^{-1}$ of $\mathrm{NaOH}$. Then, the solution was immediately heated to $100^{\circ} \mathrm{C}$ for $10 \mathrm{~min}$ to destroy untreated hexose and hexose phosphates. After cooling the solution and adding $1 \mathrm{~mL}$ of $0.1 \%(\mathrm{w} / \mathrm{V})$ resorcin in $95 \%(\mathrm{v} / \mathrm{v})$ ethanol and $3.5 \mathrm{~mL}$ of $30 \%(w / v) \mathrm{HCl}$, the solution was incubated for $10 \mathrm{~min}$ at $80^{\circ} \mathrm{C}$. Sucrose content in the SPS reaction and fructose content in the SuSy reaction were calculated from a standard curve measured at $A_{480} \mathrm{~nm}$ and $A_{540} \mathrm{~nm}$, respectively.

The soluble acid invertase (Al) and neutral/alkaline invertase activities $(\mathrm{NI})$ were measured by incubating $100 \mu \mathrm{L}$ of extract, $200 \mu \mathrm{L}$ of $1 \mathrm{M}$ sucrose, and either $2.2 \mathrm{~mL}$ of $200 \mathrm{mM}$ acetic acid- $\mathrm{NaOH}$ (pH 5.0) (for acid invertase) or $100 \mathrm{mM}$ sodium acetate-acetic acid ( $\mathrm{pH} \mathrm{7.5)} \mathrm{(for} \mathrm{alkaline} \mathrm{invertase)} \mathrm{at} 30^{\circ} \mathrm{C}$ for 30 min. The reaction was stopped with $1 \mathrm{~mL}$ of 3,5-dintrosalicylic acid (DNS) and boiling for $5 \mathrm{~min}$. According to the method described by Hu et al. 2018 [72], glucose contents in Al and NI reactions were measured spectrophotometrically at $A_{540} \mathrm{~nm}$, respectively.

\section{RNA extraction and complementary DNA synthesis}

Soybean leaf and seed tissues were harvested, and total RNA was isolated from each sample using a MiniBEST Universal RNA Extraction Kit (Takara, Kusatsu, Japan) according to the manufacturer's protocol. RNA quantity and integrity were checked by optical density at $260 \mathrm{~nm}$ and $1.0 \%$ agar gel 
electrophoresis, respectively. Single-stranded cDNA was synthesized from $1 \mu \mathrm{g}$ of total RNA using a PrimeScript ${ }^{\mathrm{TM}}$ RT Reagent Kit (Perfect Real Time) (Takara).

\section{Gene expression by qRT-PCR}

For each sample, $1 \mu \mathrm{L}$ of a reaction mixture was used for qRT-PCR in a $20-\mu \mathrm{L}$ total reaction volume using TransScript ${ }^{\circledR}$ Top Green qPCR SuperMix (TransScript, Beijing, PR China). Two reference genes, GmEF1a and GmEF1b, were selected for examination in this study [74]. The following thermal cycle conditions were used: $95^{\circ} \mathrm{C}$ for $1 \mathrm{~min}$, followed by 39 cycles of $95^{\circ} \mathrm{C}$ for $5 \mathrm{~s}, 58^{\circ} \mathrm{C}$ for $20 \mathrm{~s}$, and $60^{\circ} \mathrm{C}$ for $20 \mathrm{~s}$. The relative expression was determined according to the $2^{-\triangle \Delta \mathrm{Ct}}$ method. The gene-specific primers are listed in Supplemental Table S1.

\section{Statistical analysis}

The data were analyzed using a three-way analysis of variance (ANOVA), as implemented in the SPSS statistic package Version 17.0 (SPSS Inc., Chicago, IL, USA), and the differences between the means were compared using Tukey's multiple range test (at a $P<0.05$ significance threshold), with significant differences indicated by different letters above the bars in each figure. The data presented are means $( \pm$ $\mathrm{SD}$ ) of three independent experiments.

\section{Abbreviations}

SPS: Sucrose phosphate synthase; UDPG: Uridine diphosphate glucose; SuSy: Sucrose synthase; NI: Cytoplasmic neutral/alkaline invertase; Al: Acid invertase; SWEETs: SWEETs transporter family; SUC: Sucrose transporter; ABA: Abscisic acid; PN: Net photosynthesis rate; CV.SN17: Shennong17 cultivar; CV.SN8: Shennong8 cultivar; CV.SN12: Shennong12 cultivar; DAF: Day after flowering; G: Genotype; S: Plant growth stage; T: Treatment

\section{Declarations}

\section{Ethics approval and consent to participate}

Not applicable.

\section{Consent for publication}

Not applicable.

\section{Availability of data and materials}


The data that support the results are included within the article and its additional file. Other relevant materials are available from the corresponding authors on reasonable request.

\section{Competing interests}

The authors declare that they have no competing interests.

\section{Funding}

This work was supported by the project [2017YFD0101306-04] "National Key Research and Development Plan of Ministry of Science and Technology" and the project [2018416023] of Liaoning Provincial Department of Science and Technology. The funding agents only provided the financial support but did not participate in the design and implementation of the experimental, analysis of data and in the writing of the manuscript.

\section{Authors' contributions}

FX and YD designed research; YD, QZ, LC, XY, HZ and JW performed research; YD analyzed the data and wrote the paper; QZ, BZ and FX revised the paper. All authors read and approved the final manuscript.

\section{Acknowledgements}

Not applicable.

\section{References}

1.Mertz-Henning L, Ferreira L, Henning F, Mandarino J, Santos E, Oliveira M, et al. Effect of water deficitinduced at vegetative and reproductive stages on protein and oil content in soybean grains. Agronomy. 2017, 8(1):3.

2.Dornbos D, Mullen R. Soybean seed protein and oil contents and fatty acid composition adjustments by drought and temperature. J Am Oil Chem Soc. 1992, 69(3):228-231.

3.Zandalinas SI, Mittler R, Balfagón D, Arbona V, Gómez-Cadenas A. Plant adaptations to the combination of drought and high temperatures. Physiol Plantarum. 2018, 162(1):2-12.

4.Awasthi R, Kaushal N, Vadez V, Turner NC, Berger J, Siddique KH, et al. Individual and combined effects of transient drought and heat stress on carbon assimilation and seed filling in chickpea. Funct Plant Biol. 2014, 41(11):1148-1167. 
5.Farooq M, Gogoi N, Barthakur S, Baroowa B, Bharadwaj N, Alghamdi SS, et al. Drought stress in grain legumes during reproduction and grain filling. J Agron Crop Sci. 2017, 203(2):81-102.

6.Ruan YL, Jin Y, Yang YJ, Li GJ, Boyer JS. Sugar input, metabolism, and signaling mediated by invertase: roles in development, yield potential, and response to drought and heat. Mol Plant. 2010, 3(6):942-955.

7.Ruan YL. Signaling role of sucrose metabolism in development. Mol Plant. 2012, 5(4):763-765.

8.Stitt M. Control analysis of photosynthetic sucrose synthesis: assignment of elasticity coefficients and flux-control coefficients to the cytosolic fructose 1, 6-bisphosphatase and sucrose phosphate synthase. Philosophical Transactions of the Royal Society of London B, Biological Sciences. 1989, 323(1216):327338.

9.Cséke C, Buchanan BB. Regulation of the formation and utilization of photosynthate in leaves. Biochim Biophys Acta. 1986, 853(1):43-63.

10.Roitsch T, González MC. Function and regulation of plant invertases: sweet sensations. Trends Plant Sci. 2004, 9(12):606-613.

11.Sturm A. Invertases. Primary structures, functions, and roles in plant development and sucrose partitioning. Plant Physiol. 1999, 121(1):1-8.

12.Xu W, Cui K, Xu A, Nie L, Huang J, Peng S. Drought stress condition increases root to shoot ratio via alteration of carbohydrate partitioning and enzymatic activity in rice seedlings. Acta Physiol Plant. 2015, 37(2):9.

13.Liu F, Jensen CR, Andersen MN. Drought stress effect on carbohydrate concentration in soybean leaves and pods during early reproductive development: its implication in altering pod set. Field Crop Res. 2004, 86(1):1-13.

14.Crespi MD, Zabaleta EJ, Pontis HG, Salerno GL. Sucrose synthase expression during cold acclimation in wheat. Plant Physiol. 1991, 96(3):887-891.

15.Ruan YL. Sucrose metabolism: gateway to diverse carbon use and sugar signaling. Annu Rev Plant Biol. 2014, 65:33-67.

16.Kakumanu A, Ambavaram MM, Klumas C, Krishnan A, Batlang U, Myers E, et al. Effects of drought on gene expression in maize reproductive and leaf meristem tissue revealed by RNA-Seq. Plant Physiol. 2012, 160(2):846-867.

17.Kuai J, Liu Z, Wang Y, Meng Y, Chen B, Zhao W, et al. Waterlogging during flowering and boll forming stages affects sucrose metabolism in the leaves subtending the cotton boll and its relationship with boll weight. Plant Sci. 2014, 223:79-98. 
18.Zhang CX, Feng BH, Chen TT, Fu WM, Li HB, Li GY, et al. Heat stress-reduced kernel weight in rice at anthesis is associated with impaired source-sink relationship and sugars allocation. Environ. Exp. Bot. $2018,155: 718-733$.

19.Dante RA, Larkins BA, Sabelli PA. Cell cycle control and seed development. Front Plant Sci. 2014, 5:493.

20.Yang J, Zhang J, Grain filling of cereals under soil drying. New Phytol. 2006, 169(2):223-236.

21.Barnabás $B$, Jäger $K$, Fehér $A$. The effect of drought and heat stress on reproductive processes in cereals. Plant Cell Environ. 2008, 31(1):11-38.

22. Halford N, Curtis T, Muttucumaru N, Postles J, Mottram D. Sugars in crop plants. Ann. Appl. Biol. 2011, 158(1):1-25.

23.De Schepper V, De Swaef T, Bauweraerts I, Steppe K. Phloem transport: a review of mechanisms and controls. J Exp Bot. 2013, 64(16):4839-4850.

24.Eom JS, Choi SB, Ward JM, Jeon JS. The mechanism of phloem loading in rice (Oryza sativa).. Molecules and cells. 2012, 33(5):431-438.

25.Scofield GN, Hirose T, Aoki N, Furbank RT. Involvement of the sucrose transporter, OsSUT1, in the longdistance pathway for assimilate transport in rice. J Exp Bot. 2007, 58(12):3155-3169.

26.Ayre BG. Membrane-transport systems for sucrose in relation to whole-plant carbon partitioning. Mol Plant. 2011, 4(3):377-394.

27. Bihmidine S, Hunter III CT, Johns CE, Koch KE, Braun DM. Regulation of assimilate import into sink organs: update on molecular drivers of sink strength. Front Plant Sci. 2013, 4:177.

28.Chen LQ. SWEET sugar transporters for phloem transport and pathogen nutrition. New Phytol. 2014, 201(4):1150-1155.

29.Yadav UP, Ayre BG, Bush DR. Transgenic approaches to altering carbon and nitrogen partitioning in whole plants: assessing the potential to improve crop yields and nutritional quality. Front Plant Sci. 2015, 6:275.

30.Chen LQ, Qu XQ, Hou BH, Sosso D, Osorio S, Fernie AR, et al. Sucrose efflux mediated by SWEET proteins as a key step for phloem transport. Science. 2012, 335(6065):207-211.

31.Gottwald JR, Krysan PJ, Young JC, Evert RF, Sussman MR. Genetic evidence for the in planta role of phloem-specific plasma membrane sucrose transporters. Proc Natl Acad Sci USA. 2000, 97(25):1397913984. 
32.Truernit $\mathrm{E}$, Sauer $\mathrm{N}$. The promoter of the Arabidopsis thaliana SUC2 sucrose- $\mathrm{H}^{+}$symporter gene directs expression of $\beta$-glucuronidase to the phloem: evidence for phloem loading and unloading by SUC2. Planta. 1995, 196(3):564-570.

33.Gong X, Liu M, Zhang L, Ruan Y, Ding R, Ji Y, et al. Arabidopsis AtSUC2 and AtSUC4, encoding sucrose transporters, are required for abiotic stress tolerance in an ABA-dependent pathway. Physiol Plantarum. $2015,153(1): 119-136$.

34.Durand M, Porcheron B, Hennion N, Maurousset L, Lemoine R, Pourtau N. Water deficit enhances C export to the roots in Arabidopsis thaliana plants with contribution of sucrose transporters in both shoot and roots. Plant Physiol. 2016, 170(3):1460-1479.

35.Phan T, Ishibashi Y, Miyazaki M, Tran H, Okamura K, Tanaka S, et al. High temperature-induced repression of the rice sucrose transporter (OSSUT1) and starch synthesis-related genes in sink and source organs at milky ripening stage causes chalky grains. J Agron Crop Sci.2013, 199(3):178-188.

36.Patil G, Valliyodan B, Deshmukh R, Prince S, Nicander B, Zhao M, et al. Soybean (Glycine max) SWEET gene family: insights through comparative genomics, transcriptome profiling and whole genome resequence analysis. BMC Genomics. 2015, 16(1):520.

37. Dybing CD, Ghiasi H, Paech C. Biochemical characterization of soybean ovary growth from anthesis to abscission of aborting ovaries. Plant Physiol. 1986, 81(4):1069-1074.

38.Samarah N, Alqudah A, Amayreh J, McAndrews G. The effect of late-terminal drought stress on yield components of four barley cultivars. J Agron Crop Sci. 2009, 195(6):427-441.

39.Anjum SA, Xie XY, Wang LC, Saleem MF, Man C, Lei W. Morphological, physiological and biochemical responses of plants to drought stress. Afr. J. Agric. Res. 2011, 6(9):2026-2032.

40.Pinheiro C, Rodrigues AP, de Carvalho IS, Chaves MM, Ricardo CP. Sugar metabolism in developing lupin seeds is affected by a short-term water deficit. J Exp Bot. 2005, 56(420):2705-2712.

41.Lobato A, Neto M, Meirelles A, Silva L, Marochio C, Monteiro E, et al. Relationship between leaf relative water content and total soluble proteins in soybean exposed to short water deficit. Res J Biol Sci. 2009, 4(9):1061-1067.

42.Masoumi H, Masoumi M, Darvish F, Daneshian J, Nourmohammadi G, Habibi D. Change in several antioxidant enzymes activity and seed yield by water deficit stress in soybean (Glycine max L.) cultivars. Notulae Botanicae Horti Agrobotanici Cluj-Napoca. 2010, 38(3):86-94.

43. Hessini K, Martínez JP, Gandour M, Albouchi A, Soltani A, Abdelly C. Effect of water stress on growth, osmotic adjustment, cell wall elasticity and water-use efficiency in Spartina alterniflora. Environ. Exp. Bot. 2009, 67(2):312-319. 
44.Sperdouli I, Moustakas M. Interaction of proline, sugars, and anthocyanins during photosynthetic acclimation of Arabidopsis thaliana to drought stress. J. Plant Physiol. 2012, 169(6):577-585.

45.Muller B, Pantin F, Génard M, Turc O, Freixes S, Piques M, et al. Water deficits uncouple growth from photosynthesis, increase $\mathrm{C}$ content, and modify the relationships between $\mathrm{C}$ and growth in sink organs. $\mathrm{J}$ Exp Bot. 2011, 62(6):1715-1729.

46.Bolouri-Moghaddam MR, Le Roy K, Xiang L, Rolland F, Van den Ende W. Sugar signalling and antioxidant network connections in plant cells. FEBS J. 2010, 277(9):2022-2037.

47.Van den Ende W, Valluru R. Sucrose, sucrosyl oligosaccharides, and oxidative stress: scavenging and salvaging? J Exp Bot. 2008, 60(1):9-18.

48.Shu H, Zhou Z, Xu N, Wang Y, Zheng M. Sucrose metabolism in cotton (Gossypium hirsutum L.) fibre under low temperature during fibre development. Eur. J. Agron.2009, 31(2):61-68.

49.Koch K. Sucrose metabolism: regulatory mechanisms and pivotal roles in sugar sensing and plant development. Curr Opin Plant Biol. 2004, 7(3):235-246.

50.Rolland F, Baena-Gonzalez E, Sheen J. Sugar sensing and signaling in plants: conserved and novel mechanisms. Annu Rev Plant Biol. 2006, 57:675-709.

51. Hendrix D, Mauney J, Kimball B, Lewin K, Nagy J, Hendrey G. Influence of elevated $\mathrm{CO}_{2}$ and mild water stress on nonstructural carbohydrates in field-grown cotton tissues. Agric. For. Meteorol. 1994, 70(14):153-162.

52.Valerio $C$, Costa A, Marri L, Issakidis-Bourguet E, Pupillo $P$, Trost $P$, et al. Thioredoxin-regulated $\beta$ amylase (BAM1) triggers diurnal starch degradation in guard cells, and in mesophyll cells under osmotic stress. J Exp Bot. 2010, 62(2):545-555.

53.Zanella M, Borghi GL, Pirone C, Thalmann M, Pazmino D, Costa A, et al. $\beta$-amylase 1 (BAM1) degrades transitory starch to sustain proline biosynthesis during drought stress. J Exp Bot. 2016, 67(6):18191826.

54.Yu SM, Lo SF, Ho THD. Source-sink communication: regulated by hormone, nutrient, and stress crosssignaling. Trends Plant Sci. 2015, 20(12):844-857.

55.Chen LQ, Lin IW, Qu XQ, Sosso D, McFarlane HE, Londoño A, et al. A cascade of sequentially expressed sucrose transporters in the seed coat and endosperm provides nutrition for the Arabidopsis embryo. Plant Cell.2015, 27(3):607-619.

56.Dasgupta K, Khadilkar AS, Sulpice R, Pant B, Scheible WR, Fisahn J, et al. Expression of sucrose transporter cDNAs speciically in companion cells enhances phloem loading and long-distance transport 
of sucrose but leads to an inhibition of growth and the perception of a phosphate limitation. Plant Physiol. 2014, 165(2): 715-731.

57.Patrick J, Offler C. Post-sieve element transport of sucrose in developing seeds. Funct Plant Biol. 1995, 22(4):681-702.

58.Baud S, Wuilleme S, Lemoine R, Kronenberger J, Caboche M, Lepiniec L, et al. The AtSUC5 sucrose transporter specifically expressed in the endosperm is involved in early seed development in Arabidopsis. Plant J. 2005, 43(6):824-836.

59.Gambín BL, Borrás L, Otegui ME. Kernel water relations and duration of grain filling in maize temperate hybrids. Field Crop Res. 2007, 101(1):1-9.

60.Sehgal A, Sita K, Kumar J, Kumar S, Singh S, Siddique KH, et al. Effects of drought, heat and their interaction on the growth, yield and photosynthetic function of lentil (Lens culinaris Medikus) genotypes varying in heat and drought sensitivity. Front Plant Sci. 2017, 8:1776.

61.Huber SC, Huber JL. Role and regulation of sucrose-phosphate synthase in higher plants. Annu Rev Plant Biol. 1996, 47(1):431-444.

62. Weber H, Heim U, Golombek S, Borisjuk L, Wobus U. Assimilate uptake and the regulation of seed development. Seed Sci. Res.1998, 8(3):331-346.

63.Hu W, Ma Y, Lv F, Liu J, Zhao W, Chen B, et al. Effects of late planting and shading on sucrose metabolism in cotton fiber. Environ. Exp. Bot. 2016, 131:164-172.

64.Andersen MN, Asch F, Wu Y, Jensen CR, Næsted H, Mogensen VO, et al. Soluble invertase expression is an early target of drought stress during the critical, abortion-sensitive phase of young ovary development in maize. Plant Physiol. 2002, 130(2):591-604.

65.Wang E, Wang J, Zhu X, Hao W, Wang L, Li Q, et al. Control of rice grain-filling and yield by a gene with a potential signature of domestication. Nat. Genet. 2008, 40(11):1370.

66.Wang L, Ruan YL. New insights into roles of cell wall invertase in early seed development revealed by comprehensive spatial and temporal expression patterns of GhCWIN1 in cotton. Plant Physiol. 2012, 160(2):777-787.

67.Tang X, Su T, Han M, Wei L, Wang W, Yu Z, et al. Suppression of extracellular invertase inhibitor gene expression improves seed weight in soybean (G/ycine max).. J Exp Bot. 2016, 68(3):469-482.

68.Zanor MI, Osorio S, Nunes-Nesi A, Carrari F, Lohse M, Usadel B, et al. RNA interference of LIN5 in tomato confirms its role in controlling Brix content, uncovers the influence of sugars on the levels of fruit hormones, and demonstrates the importance of sucrose cleavage for normal fruit development and fertility. Plant Physiol. 2009, 150(3):1204-1218. 
69. Hirose T, Scofield GN, Terao T. An expression analysis profile for the entire sucrose synthase gene family in rice. Plant Sci. 2008, 174(5):534-543.

70.Fehr W, Caviness C, Burmood D, Pennington J. Stage of development descriptions for soybeans, Glycine max (L.) Merr. Crop Sci. 1971, 11(6):929-931.

71.Li S, Teng F, Rao D, Zhang H, Wang H, Yao X, et al. Photosynthesis of soybean cultivars released in different decades after grafting onto record-yield cultivars as rootstocks. Photosynthetica. 2017, 55(4):579-587.

72.Hu W, Loka DA, Fitzsimons TR, Zhou Z, Oosterhuis DM. Potassium deficiency limits reproductive success by altering carbohydrate and protein balances in cotton (Gossypium hirsutum L.). Environ. Exp. Bot. 2018, 145:87-94.

73.Liu J, Ma Y, Lv F, Chen J, Zhou Z, Wang Y, et al. Changes of sucrose metabolism in leaf subtending to cotton boll under cool temperature due to late planting. Field Crop Res. 2013, 144:200-211.

74.de Jesus Miranda V, Coelho RR, Viana AAB, de Oliveira Neto OB, Carneiro RMDG, Rocha TL, et al. Validation of reference genes aiming accurate normalization of qPCR data in soybean upon nematode parasitism and insect attack. BMC Res Notes. 2013, 6(1):196.

\section{Tables}

Table 1 Analysis of variance in $P_{\mathrm{N}}$, shoot biomass, sugar contents, and sucrose metabolism-related parameters in shoots of three soybean cultivars. 


\begin{tabular}{|c|c|c|c|c|c|c|c|}
\hline \multirow[t]{3}{*}{ Traits (/plant) } & \multicolumn{7}{|c|}{ Source of variations } \\
\hline & Growth Stage (S) & Genotype (G) & Treatment (T) & $\mathrm{S} \times \mathrm{G}$ & $\mathrm{S} \times \mathrm{T}$ & $\mathrm{G} \times \mathrm{T}$ & $\mathrm{S} \times \mathrm{G} \times T$ \\
\hline & $(d f=2)$ & $(\mathrm{df}=2)$ & $(\mathrm{df}=1)$ & $(d f=4)$ & $(\mathrm{df}=2)$ & $(d f=2)$ & $(\mathrm{df}=4)$ \\
\hline$P_{\mathrm{N}}\left[\mu \mathrm{mol}(\mathrm{CO} 2) \mathrm{m}^{-2} \mathrm{~s}^{-1}\right]$ & $\star \star$ & $\star \star$ & $\star \star$ & $\star \star$ & $\star \star$ & $\star \star$ & $\star \star$ \\
\hline shoot biomass (g) & $\star \star$ & $\star \star$ & $\star \star$ & $\star \star$ & $\star \star$ & $\star \star$ & $\star \star$ \\
\hline Starch (mg/g) & $\star \star$ & $\star \star$ & $\star \star$ & NS & $\star \star$ & $\star \star$ & * \\
\hline Sucrose (mg/g) & $\star \star$ & ** & $\star \star$ & $\star \star$ & $\star \star$ & $\star \star$ & $\star \star$ \\
\hline Fructose (mg/g) & $\star \star$ & $\star \star$ & $\star \star$ & $\star \star$ & $\star \star$ & $\star \star$ & $\star \star$ \\
\hline Glucose (mg/g) & $\star \star$ & ** & $\star \star$ & $\star \star$ & NS & NS & NS \\
\hline SPS (mmol sucrose $\mathrm{mg}^{-1}$ protein $\mathrm{h}^{-1}$ ) & $\star \star$ & $\star \star$ & $\star \star$ & $\star \star$ & $\star \star$ & * & NS \\
\hline SuSy (mmol glucose $\mathrm{mg}^{-1}$ protein $\mathrm{h}^{-1}$ ) & $\star \star$ & $\star \star$ & $\star \star$ & $\star \star$ & $\star \star$ & NS & * \\
\hline Al (mmol glucose $\mathrm{mg}^{-1}$ protein $\mathrm{h}^{-1}$ ) & $\star \star$ & $\star \star$ & ** & $\star \star \star$ & $\star \star$ & $\star \star$ & ** \\
\hline $\mathrm{NI}\left(\mathrm{mmol}\right.$ glucose $\mathrm{mg}^{-1}$ protein $\left.\mathrm{h}^{-1}\right)$ & $\star \star$ & $\star \star$ & NS & $\star \star$ & * & $\star \star$ & $\star \star$ \\
\hline GmSUC2 & $\star \star$ & $\star \star$ & $\star \star$ & $\star \star$ & $\star \star$ & NS & ** \\
\hline GmSWEET6 & $\star \star$ & ** & $\star \star$ & $\star \star$ & $\star \star$ & $\star \star$ & ** \\
\hline GmSWEET15 & $\star \star$ & $\star \star$ & $\star \star$ & $\star \star$ & $\star \star$ & $\star \star$ & $\star \star$ \\
\hline GmSPS1 & $\star \star$ & $\star \star$ & $\star \star$ & $\star \star$ & $\star \star$ & $\star \star$ & $\star \star$ \\
\hline GmSPS2 & $\star \star$ & $\star \star$ & $\star \star$ & $\star \star$ & $\star \star$ & $\star \star$ & $\star \star$ \\
\hline GmSPS3 & $\star \star$ & $\star \star$ & $\star \star$ & $\star \star$ & $\star \star$ & $\star \star$ & $\star \star$ \\
\hline GmSPS4 & $\star \star$ & $\star \star$ & $\star \star$ & $\star \star$ & $\star \star$ & $\star \star$ & $\star \star$ \\
\hline GmSuSy 1 & $\star \star$ & $\star \star$ & $\star \star$ & $\star \star$ & $\star \star$ & $\star \star$ & $\star \star$ \\
\hline GmSuSy2 & $\star \star$ & $\star \star$ & $\star \star$ & $\star \star$ & $\star \star$ & $\star \star$ & $\star \star$ \\
\hline$G m C-I N V$ & $\star \star$ & $\star \star$ & $\star \star$ & $\star \star$ & $\star \star$ & $\star \star$ & $\star \star$ \\
\hline GmA-INV & $\star \star$ & $\star \star$ & $\star \star$ & $\star \star$ & $\star \star$ & $\star \star$ & $\star \star$ \\
\hline
\end{tabular}

* and ** indicate significance at the 0.05 and 0.01 probability levels, respectively. NS, Not significant.

Table 2 Analysis of variance in seed weight, sugar contents, and sucrose metabolism-related parameters in the seeds of three soybean cultivars. 


\begin{tabular}{|c|c|c|c|c|c|c|c|}
\hline \multirow[t]{3}{*}{ Traits (/plant) } & \multicolumn{7}{|c|}{ Source of variations } \\
\hline & Growth Stage (S) & Genotype (G) & Treatment (T) & $\mathrm{S} \times \mathrm{G}$ & $\mathrm{S} \times \mathrm{T}$ & $\mathrm{G} \times \mathrm{T}$ & $\mathrm{S} \times \mathrm{G} \times \mathrm{T}$ \\
\hline & $(d f=2)$ & $(\mathrm{df}=2)$ & $(d f=1)$ & $(d f=4)$ & $(d f=2)$ & $(\mathrm{df}=2)$ & $(\mathrm{df}=4)$ \\
\hline Seed weight (g) & ** & ** & $\star \star$ & $\star \star$ & $\star \star$ & $\star \star$ & $\star *$ \\
\hline Starch (mg/g) & $\star \star$ & * & $\star \star$ & $\star \star$ & $\star \star$ & ** & $\star \star$ \\
\hline Sucrose (mg/g) & ** & ** & ** & * & $\star \star$ & ** & $\star \star$ \\
\hline Fructose (mg/g) & ** & ** & ** & $\star \star$ & $\star \star$ & ** & ** \\
\hline Glucose (mg/g) & $\star \star$ & $\star \star$ & $\star \star$ & $\star \star$ & $\star \star$ & $\star \star$ & $\star \star$ \\
\hline SPS (mmol sucrose $\mathrm{mg}^{-1}$ protein $\mathrm{h}^{-1}$ ) & ** & ** & $\star \star$ & $\star \star$ & $\star \star$ & NS & ** \\
\hline SuSy (mmol glucose $\mathrm{mg}^{-1}$ protein $\mathrm{h}^{-1}$ ) & ** & $\star \star$ & $\star \star$ & $\star \star$ & $\star \star$ & $\star \star$ & ** \\
\hline $\mathrm{Al}\left(\mathrm{mmol}\right.$ glucose $\mathrm{mg}^{-1}$ protein $\left.\mathrm{h}^{-1}\right)$ & NS & ** & ** & NS & ** & $\star \star$ & ** \\
\hline $\mathrm{NI}\left(\mathrm{mmol}\right.$ glucose $\mathrm{mg}^{-1}$ protein $\left.\mathrm{h}^{-1}\right)$ & ** & $\star \star$ & $\star \star$ & $\star \star$ & $\star \star$ & $\star \star$ & ** \\
\hline GmSUC2 & ** & ** & ** & $\star \star *$ & ** & $\star \star *$ & ** \\
\hline GmSWEET12 & $\star \star$ & $\star \star$ & $\star \star$ & $\star \star$ & $\star \star$ & $\star \star$ & $\star \star$ \\
\hline GmSWEET21 & $\star \star$ & $\star \star$ & $\star \star$ & $\star \star$ & $\star \star$ & $\star \star$ & $\star \star$ \\
\hline GmSPS1 & $\star \star$ & $\star \star$ & $\star \star$ & $\star \star$ & $\star \star$ & $\star \star$ & $\star \star$ \\
\hline GmSPS2 & $\star \star$ & $\star \star$ & $\star \star$ & $\star \star$ & $\star \star$ & $\star \star$ & $\star \star$ \\
\hline GmSPS3 & $\star \star$ & $\star \star$ & $\star \star$ & $\star \star$ & $\star \star$ & $\star \star$ & $\star \star$ \\
\hline GmSPS4 & $\star \star$ & $\star \star$ & NS & $\star \star$ & $\star \star$ & $\star \star$ & $\star \star$ \\
\hline GmSuSy 1 & $\star \star$ & $\star \star$ & $\star \star$ & $\star \star$ & $\star \star$ & NS & $\star \star$ \\
\hline GmSuSy2 & $\star \star$ & $\star \star$ & $\star \star$ & $\star \star$ & $\star \star$ & $\star \star$ & $\star \star$ \\
\hline$G m C-I N V$ & $\star \star$ & $\star \star$ & $\star \star$ & $\star \star$ & $\star \star$ & ** & ** \\
\hline$G m A-I N V$ & $\star \star$ & $\star \star$ & $\star \star$ & $\star \star$ & $\star \star$ & $\star \star$ & $\star \star$ \\
\hline
\end{tabular}

* and ** indicate significance at the 0.05 and 0.01 probability levels, respectively. NS, Not significant.

\section{Figures}




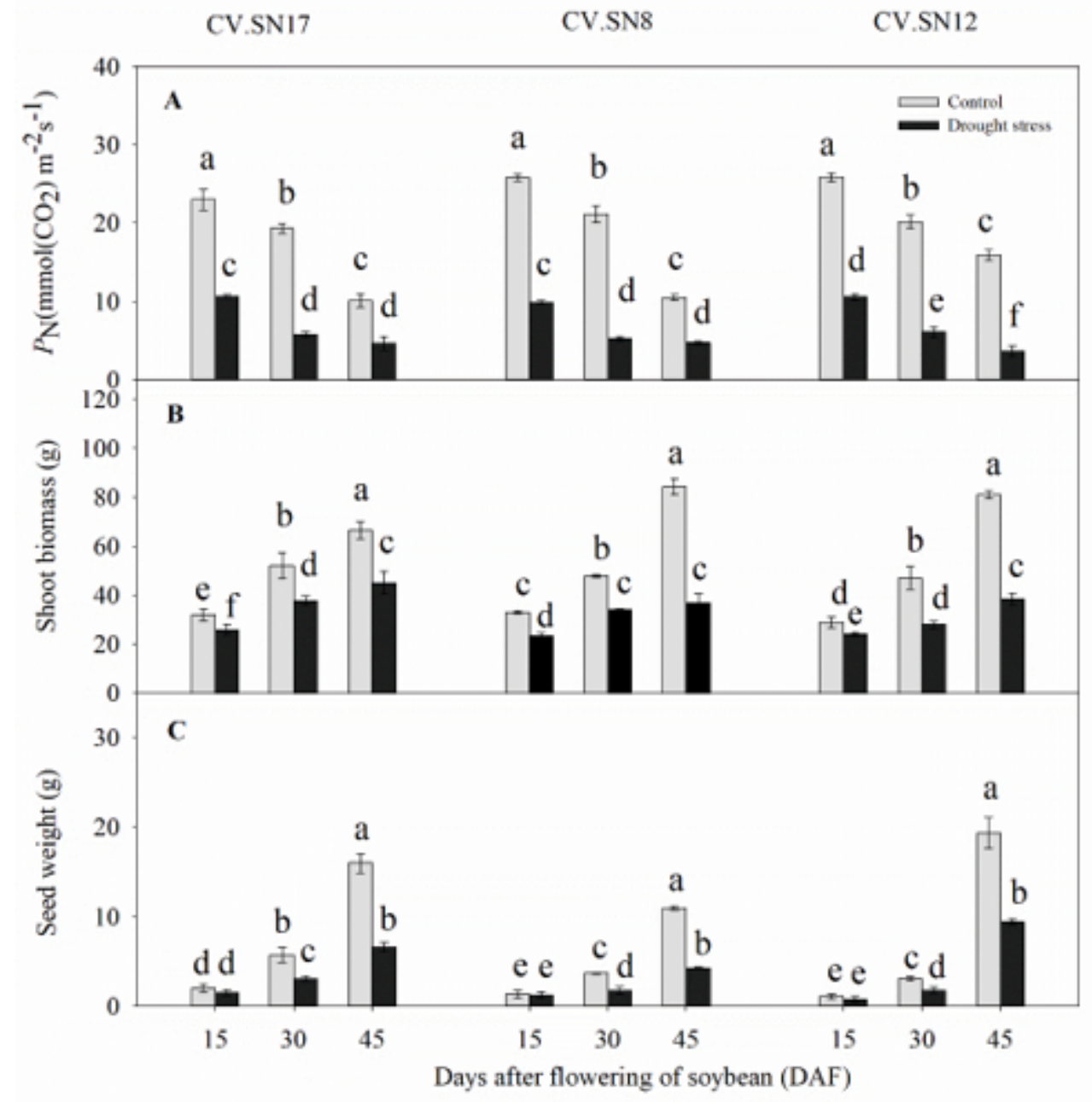

Figure 1

Effect of drought stress on photosynthesis rate, shoot biomass, and seed weight in different soybean cultivars. (A) The photosynthesis rates, (B) shoot biomass totals, and (C) seed weights of CV.SN17, CV.SN8, and CV.SN12. Data are means \pm standard deviations of at least three samples. Different letters above vertical bars indicate significant differences between means at a $\mathrm{P}<0.05$ level. 


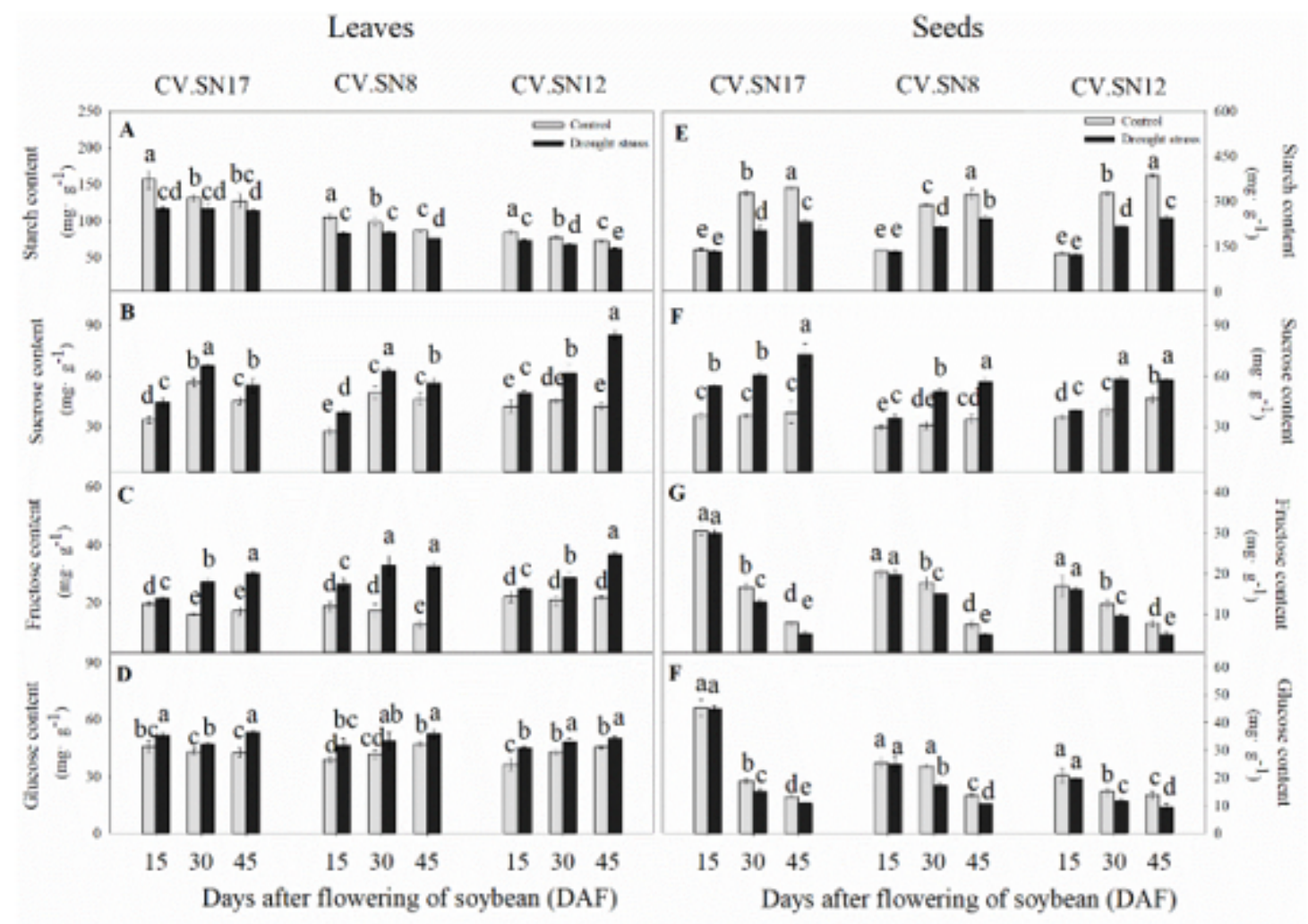

Figure 2

Effect of drought stress on the (A) and (E) starch, (B) and (F) sucrose, (C) and (G) fructose, and (D) and (F) glucose contents of leaves and seeds. Data are means \pm standard deviations of at least three samples. Different letters above vertical bars indicate significant differences between means at a $\mathrm{P}<0.05$ level. 


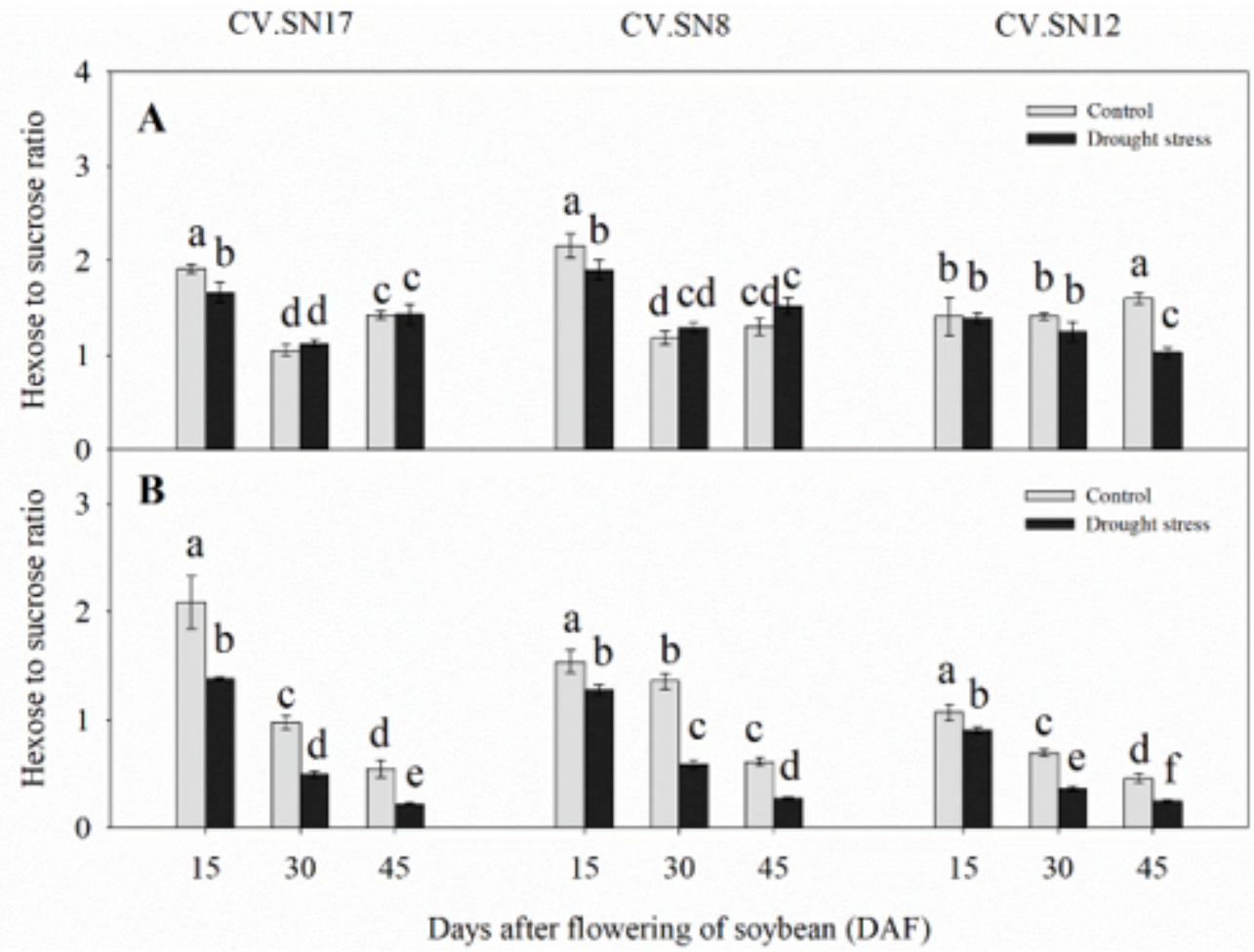

Figure 3

Effect of drought stress on hexose-to-sucrose ratio in (A) leaves and (B) seeds. Data are means \pm standard deviations of at least three samples. Different letters above vertical bars indicate significant differences between means at a $\mathrm{P}<0.05$ level.

Leaves Seeds

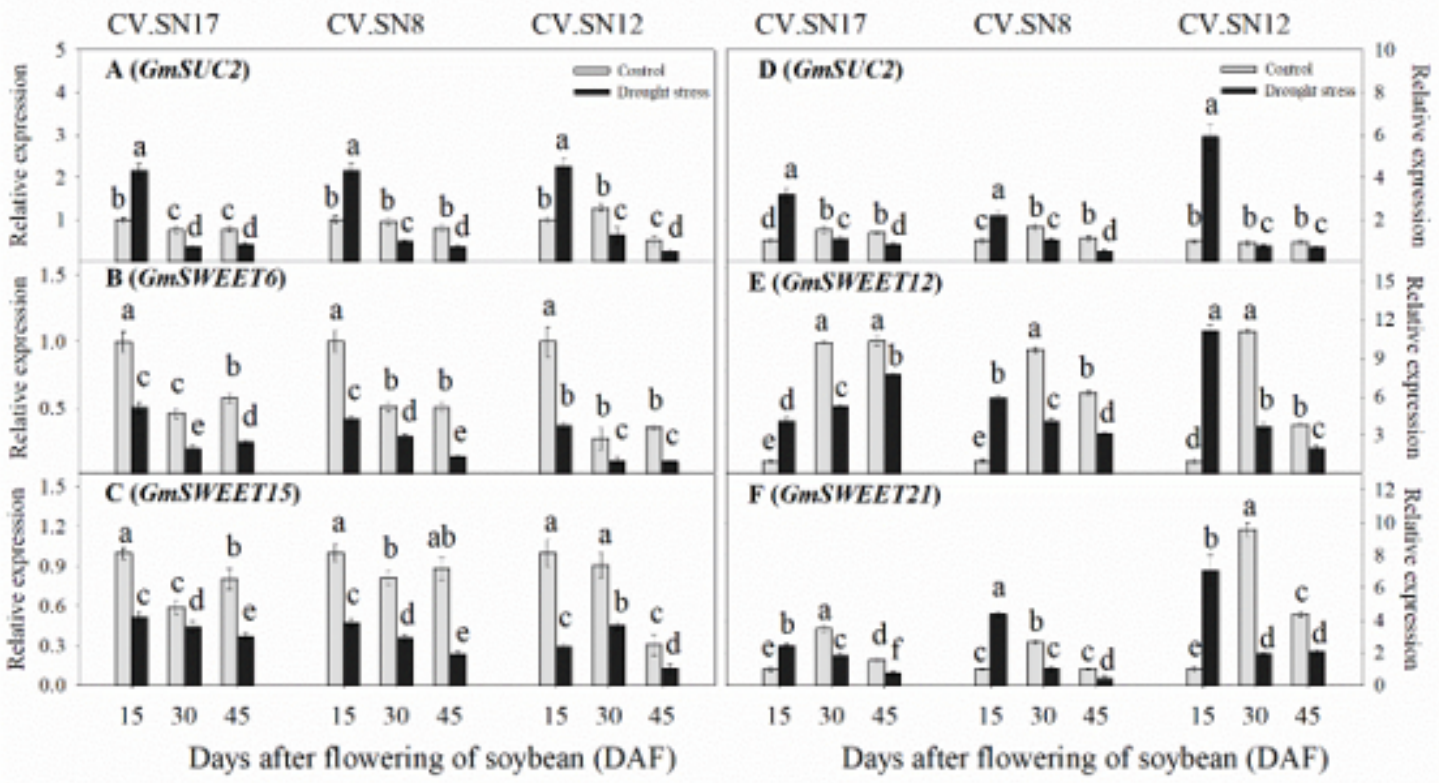

Figure 4 
Effect of drought stress on the expression levels of sucrose transporter genes in leaves and seeds. (A-C) The expression levels of GmSUC2, GmSWEET6, and GmSWEET15 in leaves. (D-F) The expression levels of GmSUC2, GmSWEET12, and GmSWEET21 in seeds. Data are means \pm standard deviation of at least three samples. Different letters above vertical bars indicate significant differences between means at a $P$ $<0.05$ level.

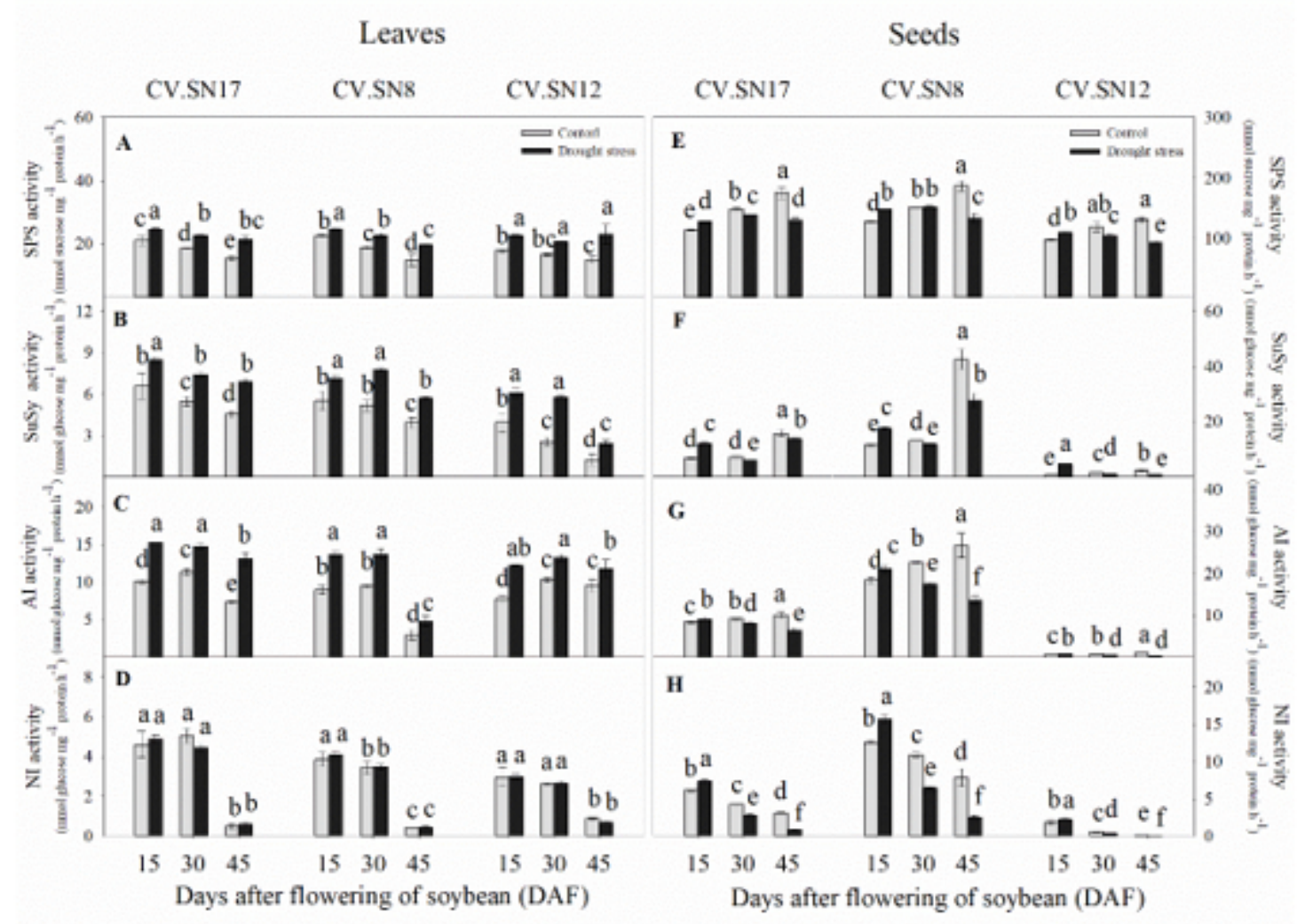

Figure 5

Effect of drought stress on the enzyme activity levels of (A) and (E) sucrose phosphate synthase (SPS), (B) and (F) sucrose synthase (SuSy), (C) and (G) acid invertase (Al), and (D) and (H) neutral/alkaline invertase $(\mathrm{NI})$ in leaves and seeds. Data are means \pm standard deviations of at least three samples. Different letters above vertical bars indicate significant differences between means at a $\mathrm{P}<0.05$ level. 
Leaves

Seeds

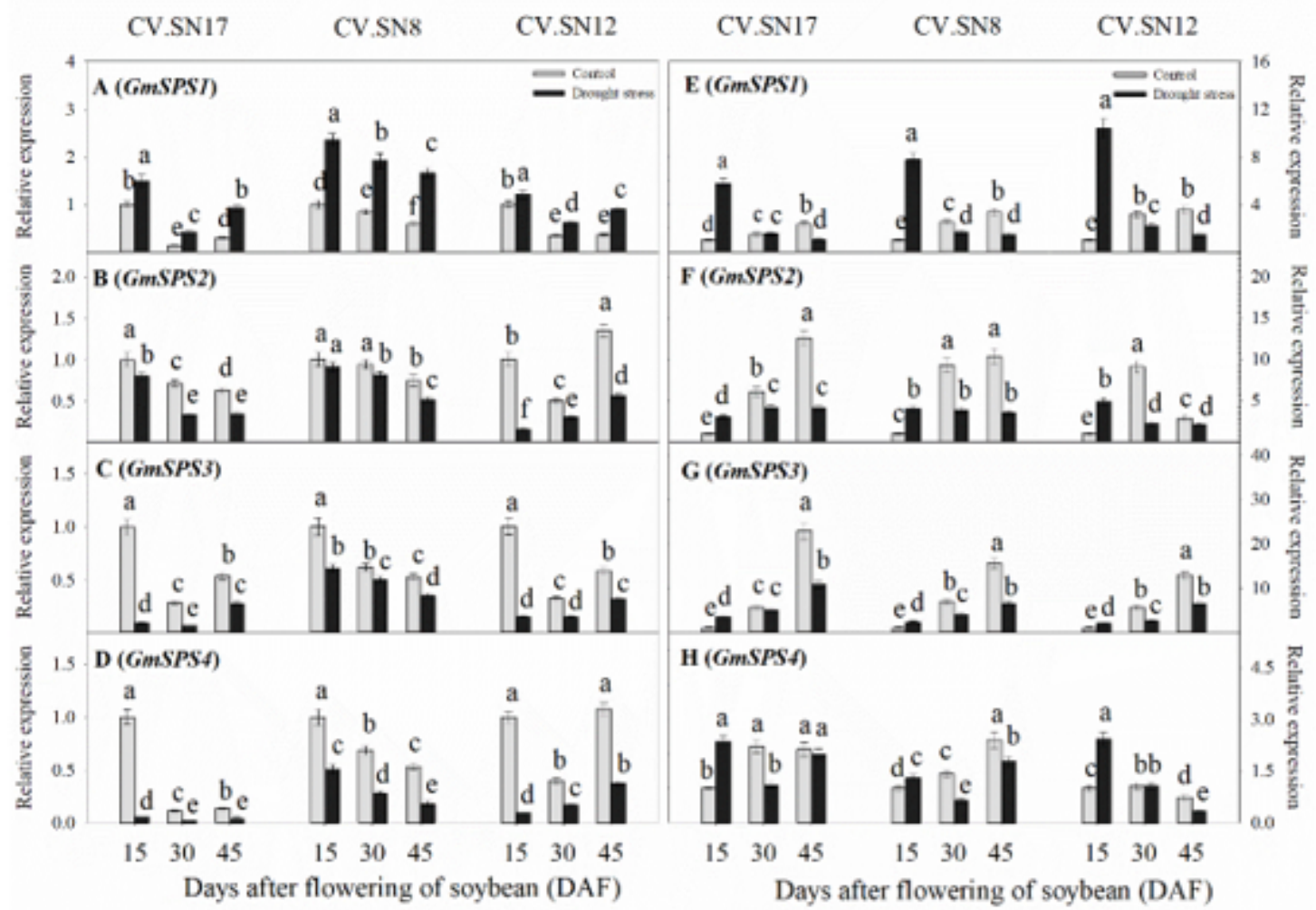

Figure 6

Effect of drought stress on the expression levels of GmSPS genes in leaves and seeds: (A) and (E) GmSPS1; (B) and (F) GmSPS2; (C) and (G) GmSPS3; (D) and (H) GmSPS4. Data are means \pm standard deviations of at least three samples. Different letters above vertical bars indicate significant differences between means at a $\mathrm{P}<0.05$ level. 
Leaves

Seeds

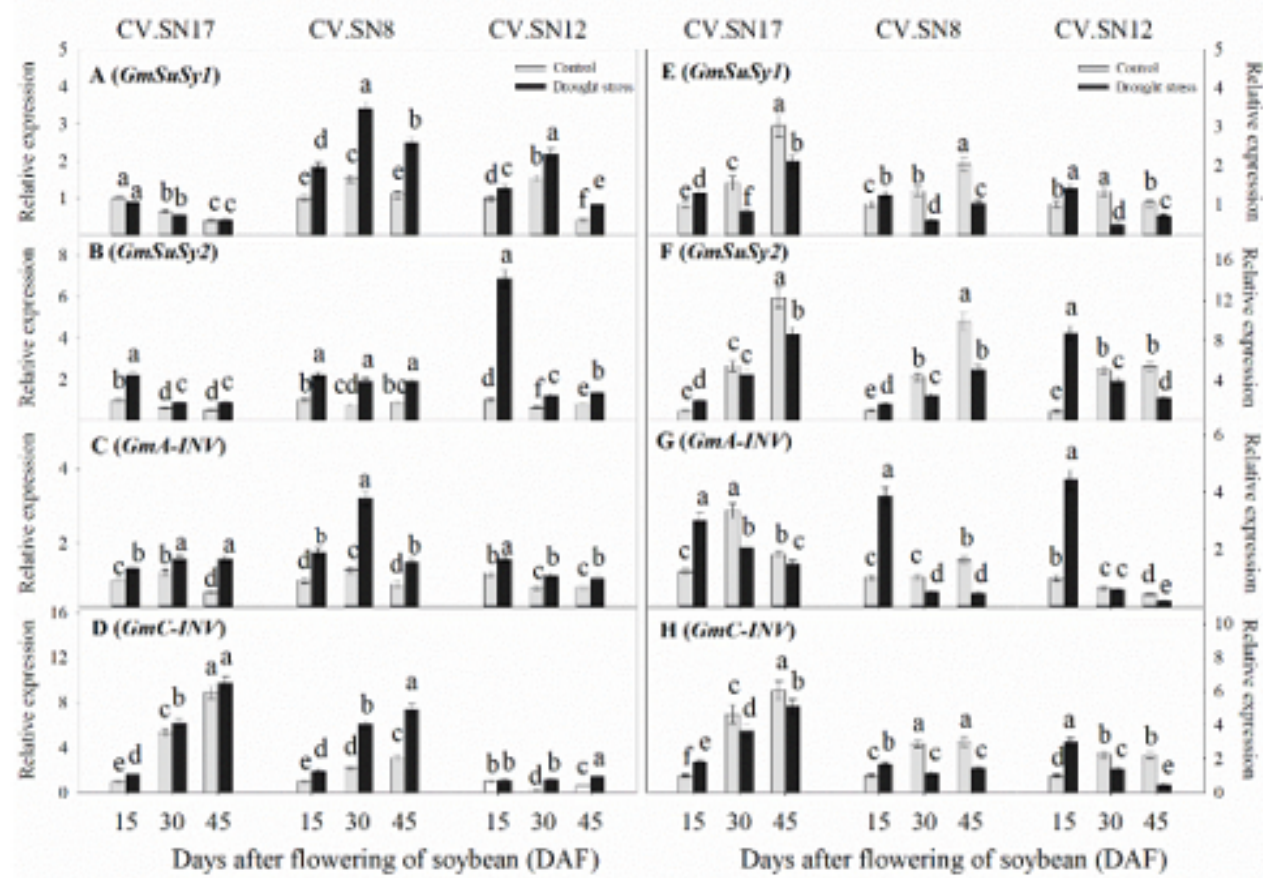

Figure 7

Effect of drought stress on the expression of (A) and (E) GmSuSy1, (B) and (F) GmSuSy2, (C) and (G) GmA-INV, and (D) and (H) GmC-INV in leaves and seeds. Data are means \pm standard deviations of at least three samples. Different letters above vertical bars indicate significant differences between means at a $P$ $<0.05$ level.

Early

Late
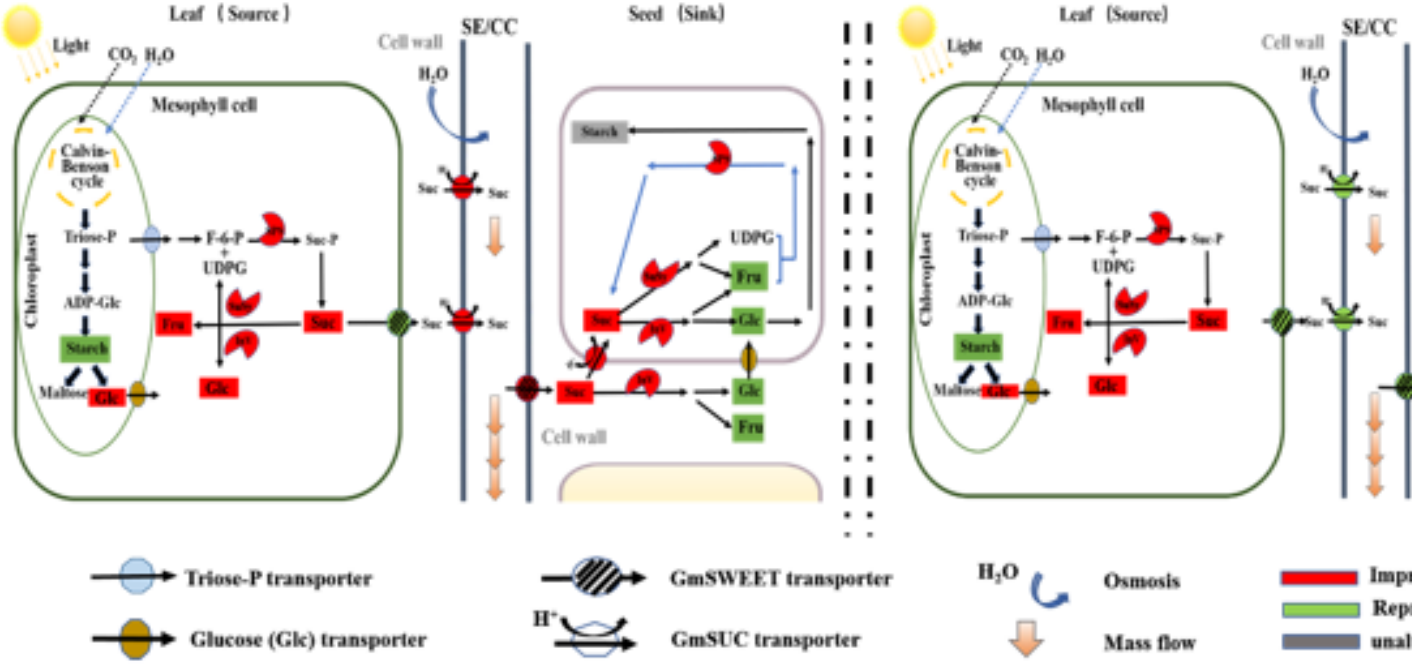

Sord (Sink)

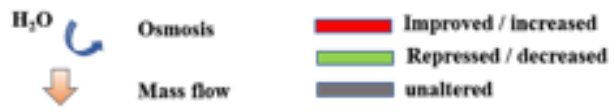

Figure 8 
A comprehensive model of sucrose (Suc) metabolism and transport for sources (leaves) and sinks (seeds) in soybean plants under drought stress. Up-regulated elements under drought stress are shown with red boxes, down-regulated elements under drought stress are shown with green boxes, and unaltered elements are shown with gray boxes.

\section{Supplementary Files}

This is a list of supplementary files associated with this preprint. Click to download.

- SupplementaryMaterial.docx 